\title{
On the Evolution of Multiple Jobholding in Canada
}

OLENA KOSTYSHYNA ETIENNE LALÉ 


\section{$>$ CIRANO Knowledge into action}

Center for Interuniversity Research and Analysis on Organizations

The purpose of the Working Papers is to disseminate the results of research conducted by CIRANO research members in order to solicit exchanges and comments. These reports are written in the style of scientific publications. The ideas and opinions expressed in these documents are solely those of the authors.

Les cahiers de la série scientifique visent à rendre accessibles les résultats des recherches effectuées par des chercheurs membres du CIRANO afin de susciter échanges et commentaires. Ces cahiers sont rédigés dans le style des publications scientifiques et n'engagent que leurs auteurs.

CIRANO is a private non-profit organization incorporated under the Quebec Companies Act. Its infrastructure and research activities are funded through fees paid by member organizations, an infrastructure grant from the government of Quebec, and grants and research mandates obtained by its research teams.

Le CIRANO est un organisme sans but lucratif constitué en vertu de la Loi des compagnies du Québec. Le financement de son infrastructure et de ses activités de recherche provient des cotisations de ses organisations-membres, d'une subvention d'infrastructure du gouvernement du Québec, de même que des subventions et mandats obtenus par ses équipes de recherche.

\section{CIRANO Partners - Les partenaires du CIRANO}

Corporate Partners - Partenaires corporatifs

Autorité des marchés financiers

Bank of Canada

Bell Canada

BMO Financial Group

Business Development Bank of Canada

Caisse de dépôt et placement du Québec

Desjardins Group

Énergir

Hydro-Québec

Innovation, Science and Economic Development Canada

Intact Financial Corporation

Manulife Canada

Ministère de l'Économie, de la Science et de l'Innovation

Ministère des finances du Québec

National Bank of Canada

Power Corporation of Canada

PSP Investments

Rio Tinto

Ville de Montréal

Academic Partners - Partenaires universitaires

Concordia University

École de technologie supérieure

École nationale d'administration publique

HEC Montréal

McGill University

National Institute for Scientific Research

Polytechnique Montréal

Université de Montréal

Université de Sherbrooke

Université du Québec

Université du Québec à Montréal

Université Laval

CIRANO collaborates with many centers and university research chairs; list available on its website. Le CIRANO collabore avec de nombreux centres et chaires de recherche universitaires dont on peut consulter la liste sur son site web.

(C) December 2020. Olena Kostyshyna, Etienne Lalé. All rights reserved. Tous droits réservés. Short sections may be quoted without explicit permission, if full credit, including (C) notice, is given to the source. Reproduction partielle permise avec citation du document source, incluant la notice (C).

The observations and viewpoints expressed in this publication are the sole responsibility of the authors; they do not necessarily represent the positions of CIRANO or its partners. Les idées et les opinions émises dans cette publication sont sous l'unique responsabilité des auteurs et ne représentent pas nécessairement les positions du CIRANO ou de ses partenaires. 


\title{
On the Evolution of Multiple Jobholding in Canada *
}

\author{
Olena Kostyshyna ‘, Etienne Lalé
}

\begin{abstract}
Résumé
The number of workers who hold more than one job (a.k.a. multiple jobholders) has increased spectacularly in Canada since the mid-1970s - it has been multiplied by almost three. In this paper, we document this historical change and provide a comprehensive account of its dynamics. To this end, we use restricted-access panel micro-data from the Canadian labour force survey to construct transition probabilities in and out of multiple jobholding. We analyze these data through the lens of a trend decomposition that separates out the role of worker inflows and outflows. The upward trend in multiple jobholding is chiefly explained by the increased likelihood of single jobholders to pick up second jobs. While economic reasons remain important among the motives that push workers towards multiple jobholding, a more flexible hours schedule in the main job may explain why taking on a second job has become more frequent.
\end{abstract}

Keywords/Mots-clés: Multiple Jobholding, Worker Flows, Long-run Trends, Business Cycles

JEL Codes/Codes JEL: E24, J21, J22, J60

\footnotetext{
${ }^{*}$ This version: December 2020. We would like to thank Yves-Emmanuel Massé François at the Federal Research Data Centre in Ottawa for his help in working with the data, as well as the editor, Fabian Lange, and three anonymous referees for useful comments that improved the paper substantially. The views expressed in this paper are solely those of the authors. No responsibility for them should be attributed to the Bank of Canada.

Lalé gratefully acknowledges financial support from Fonds de Recherche du Québec - Société et Culture (Grant acronym 2019-NP-254270) and the W.E. Upjohn Institute for Employment Research (2018 Early Career Research Grant). Any remaining errors are ours.

$\dagger$ Bank of Canada. Address: Bank of Canada, 234 Wellington Street, Ottawa (ON) K1A 0G9, Canada - Phone: +1 6137828578 -E-mail: kost@bankofcanada.ca.

* Université du Québec à Montréal, CIRANO and IZA. Address: Department of Economics, Université du Québec à Montréal, C.P. 8888, Succursale centre ville, Montréal (QC) H3C 3P8, Canada - Phone: +1 514987 3000, ext. 3680 -E-mail: lale.etienne@uqam.ca.
} 


\section{Introduction}

A popular view in the media is that multiple jobholders - workers who hold more than one job at the same time - are an indication of the economic hardships faced by many households. When the economy enters a downturn, as many working families are pushed into poverty, a common story has it that individuals combine two part-time jobs to make a full-time income. Conversely, when the economy recovers and unemployment falls, many point at the still high number of multiple jobholders as a sign of continued (but hidden) labour market slack. Again, in these circumstances it is believed that vulnerable workers (e.g., single mothers, less-educated workers, etc.) are more exposed to the burden of combining several jobs to make ends meet. ${ }^{1}$ As we show in this paper, these popular stories about multiple jobholding are only partly borne out by the data. More generally, although interest in this topic has recently been growing in the media as well as among scholars and policymakers, there is still little known about the dynamics of multiple jobholding and its underlying sources.

Our goal in this paper is to fill this gap. We use micro-data from the Canadian Labour Force Survey (LFS) to construct monthly time series of multiple jobholding over the past forty-five years. A key fact of interest, motivating our analysis, is that the share of multiple jobholders among employed workers has grown tremendously in these data: from about 2 percent in the mid-1970s to 6 percent at the end of the 2010s. The Canadian LFS is, to our knowledge, the only survey with information about multiple jobholding over such a long time span. ${ }^{2}$ Besides the long-run perspective afforded by these data, they cover the three major recessions that hit Canada's economy during the 1980s, 1990s and 2000s, which enables us to investigate the business cycle dynamics of multiple jobholding.

\footnotetext{
${ }^{1}$ For press articles relating economic hardships and multiple jobholding, see for example Davidson [2016] and Marotta [2020] respectively for the United States (U.S.) and Canada. Puzder [2018] is an example discussing whether multiple jobholding numbers support the view that the unemployment rate misses the amount of slack in the economy. Recently, in both the U.S. and Canada, concerns have emerged that many multiple jobholders might be excluded from safety net programs targeted for unemployed workers (Cohen [2020]).

${ }^{2}$ In the U.S., the Current Population Survey (CPS) started collecting information on multiple jobs in 1994 (Lalé [2016]). There exist occasional supplements of the CPS (the "Work schedules" and the "May" supplements) for some earlier periods, but they provide information on multiple jobholding only as discrete snapshots. The U.S. Panel Study of Income Dynamics contains annual information on the number of job held in the previous calendar year, starting in 1976. It is however not always clear whether these data measure multiple jobs separately from job-to-job changes that occur over a calendar year (Paxson and Sicherman [1996]). In European countries, most labour force surveys started collecting information on multiple jobholding only recently.
} 
A crucial first step to interpret changes in the number of multiple jobholders is to describe accurately the behavior of the gross worker flows that govern its evolution. As is well known at least since Akerlof and Main [1981], a picture of labour market dynamics based on stocks says little about the size and changes of the underlying inflows and outflows. ${ }^{3}$ At a more substantive level, by looking at worker flows, we aim to disentangle two driving forces that could contribute to the increase in multiple jobholding: that single jobholders have become more likely to take on second jobs, or that multiple jobholders have become less likely to give up their second job quickly. To address this question, we employ restricted-access panel data from the LFS to measure labour market flows and construct estimates of workers' probability to move in and out of multiple jobholding. We then use a statistical decomposition that allows us to quantify the role of the driving forces shaping the dynamics of multiple jobholding.

The main finding of our analysis is the clear picture that emerges from the statistical decomposition: the increase of single jobholders' likelihood to pick up second jobs explains most of the increase of multiple jobholding that has occurred over the past decades. In establishing this result, we show that it is important to distinguish multiple jobholding flows among parttime and full-time workers. Indeed, whether an individual is working full-time or part-time affects the flexibility with which s/he may combine the main job with a second job. More generally, part-time employment is a major channel of hours adjustments at the individual level (Borowczyk-Martins and Lalé [2019]), and many theories establish a direct relationship between such hours adjustments and multiple jobholding (Shishko and Rostker [1976], Krishnan [1990], Paxson and Sicherman [1996]). Related, we show that it is important to analyze the data separately by gender. For men, we find that these dynamics are chiefly driven by the behavior of full-time workers, which is unsurprising since most male multiple jobholders combine a full-time main job with a second job. The behavior of part-time workers plays a more important role among women. Interestingly, despite the very large change in the number of female multiple jobholders (it was multiplied by almost six between 1976 and 2018), the composition of multiple jobholding has remained stable, with roughly 50 percent of female multiple jobholders who work full-time on the main job.

\footnotetext{
${ }^{3}$ See, among numerous references, Darby et al. [1986], Blanchard and Diamond [1990] and Blanchard and Portugal [2001] for early important examples.
} 
In terms of business cycle dynamics, we uncover gender differences, namely that cyclical variations in multiple jobholding are lower for women than for men. Besides this, for men we find a large drop in both inflows and outflows during the recessions of the 1980s and 1990s, with roughly offsetting effects on the multiple jobholding share - what is often called a 'stock-flow fallacy' in the literature. The recessionary drop in multiple jobholding inflows suggests that multiple jobholding is, in the short run at least, driven by the arrival rate of second jobs. The drop in the outflows indicates that workers who already have a second job are less likely to give it up during downturns, when mitigating the risk of income loss is more important. We emphasize these results because the literature has been so far inconclusive on whether the push and pull factors of multiple jobholding have a strong cyclical component (Amuedo-Dorantes and Kimmel [2009], Lalé [2016], Hirsch et al. [2016]).

To obtain a deeper understanding of the results, we complement the statistical decomposition with data from two surveys that provide information about individuals' desired work schedule and main reasons for holding several jobs. We find evidence suggesting that workers enjoy a more flexible work schedule on their main job, which might explain why the probability that a single jobholder takes on a second job has increased over time. At the same time, we find that the economic motive (meeting regular household expenses, paying off debts, buying something special, and saving for the future) has not become less important as the number of multiple jobholders grew over time. In sum, it seems that holding a second job is and remains a means to generate additional income for most workers, who have more opportunities to do so because jobs are increasingly flexible in terms of work schedule.

Our paper contributes to the literature on multiple jobholding on at least two levels. First, similar to Hirsch et al. [2016], Hirsch and Winters [2016], Hirsch et al. [2017] and Lalé [2016] we analyze the behavior of time series data on multiple jobholding. We substantially expand these researches by studying a longer period of time and by providing several decompositions of how worker flows shape the dynamics of multiple jobholding, in the short run as well as in the long run. Note that all these studies use data for the U.S. labour market. In Canada, as far we are aware, the main study is that of Kimmel and Powell [1999] who documented the levels and changes of multiple jobholding between 1981 and 1995. Ours updates and enriches 
the results of Kimmel and Powell [1999] (who did not analyze worker flows). Second, our paper contributes to understanding the motives that prompt workers to take on and give up second jobs, and more generally the paths of adjustment in working hours. Related references include Shishko and Rostker [1976], Krishnan [1990], Paxson and Sicherman [1996], Conway and Kimmel [1998, 2001] and Hlouskova et al. [2017]. Much of this literature deals with the roles of 'economic reasons' vs. 'job heterogeneity' in explaining the decision to hold more than one job. ${ }^{4}$ Without discarding the relevance of job heterogeneity, we emphasize that economic reasons remain the main motive and, differently from these studies, we analyze its impact on changes in the number of multiple jobholders at the aggregate level.

The literature on multiple jobholding is growing partly because of the great interest generated by the rise of 'alternative work arrangements', that is to say alternatives to the traditional "Monday-Friday 9am-5pm" work week (Katz and Krueger [2019]). Indeed, multiple jobholding, self-employment, online gig work, project-based employment, etc. are all considered part of this broad set of new ways of working. The point we wish to make is that the overlap between multiple jobholding and alternative work arrangements is not as clear as one would think. First, multiple jobholding is not considered a form of so-called 'contingent work', unlike most other alternative work arrangements. ${ }^{5}$ Second, traditional labour market surveys are not well equipped to measure the overlap between multiple jobholding and the use of side jobs (Abraham et al. [2017]). By providing a detailed picture of who holds multiple jobs and of how their number has evolved over time, our paper can help future research in drawing the line between multiple jobholding and other types of alternative work arrangements.

The paper is organized as follows. Section 2 presents the data and main definitions. Section 3 introduces the framework of our analysis and presents some preliminary facts about multiple jobholding in Canada. Section 4 explains how we measure inflow and outflow transition probabilities and describes their time series behavior. In Section 5, we develop a statistical de-

\footnotetext{
${ }^{4}$ The ‘job heterogeneity' motive refers mainly to the enjoyment that workers derive from a job that is different from their main job (Conway and Kimmel [1998, 2001]). 'Job heterogeneity' is sometimes also understood as workers' willingness to diversify their skills (Panos et al. [2014], Pouliakas [2017]).

${ }^{5}$ For example, the "Contingent Worker" supplements of the CPS defines contingent workers as "those who do not have an explicit or implicit contract for continuing employment." None of the categories used to identify whether employment is expected to continue refer to multiple jobholding. We thank an anonymous referee for drawing our attention to this definitional aspect of contingent work.
} 
composition that separates outs the trends in multiple jobholding into the contribution of each transition probabilities. Section 6 investigates further the driving forces of multiple jobholding by looking at workers' reasons for holding more than one job. Section 7 concludes the paper.

\section{Data and definitions}

This section presents the data and definitions of the main concepts used in the analysis.

\subsection{Data sources}

We use Labour Force Survey (LFS) micro-data between January 1976 to December 2018. The LFS is a monthly household survey administered by Statistics Canada. It is the main source of information for measuring unemployment statistics in Canada and is used in the administration of the Employment Insurance program. The LFS is conducted nationwide, in provinces and territories. It is designed to be representative of the civilian non-institutionalized population in Canada. Each month, the survey collects labour force information from about 56,000 households for all household members aged 15 and over. It also collects demographic information such as gender, age, education, etc.

The LFS relies on a rotating panel design. Each household is interviewed for six consecutive months, and each month one-sixth of the sample is replaced with a new cohort of respondents (Statistics Canada [2017]). We use the panel micro-data of the LFS, which is subject to restricted access, to measure worker flows. ${ }^{6}$ To this end, we longitudinally match LFS respondents in order to determine changes in their labour force status. ${ }^{7}$ We are able to link about 94 percent of respondents from the ongoing rotation groups (that is to say respondents who have not yet completed six rounds of interview) across two consecutive months of the survey. Rotational sample attrition, which largely explains why not all respondents can be matched across surveys, will be explicitly accounted for in our measurement of transition probabilities across

\footnotetext{
${ }^{6}$ Restricted access mean that all our estimates based on worker flow data are computed inside the Federal Research Data Centre and meet the data release requirements that apply to the LFS. Statistics Canada is prohibited by law (under the Statistics Act) from releasing data which would divulge information about any identifiable person.

${ }^{7}$ We check the validity of the longitudinal links against a gender and age filter. See Appendix A for details.
} 
labour force statuses.

We also use data from two other surveys: the Survey of Work Arrangements (SWA) and the Canadian Survey of Consumer Expectations (CSCE). ${ }^{8}$ The SWA was conducted in November 1991 and 1995 by Statistics Canada as an occasional supplement to the LFS to collect information on work schedules, hours of work, flexible hours, etc. The CSCE is a representative, internet-based quarterly survey of a rotating panel of approximately 2,000 residents of Canada aged 18 or older. It is administered by a large polling firm on behalf of the Bank of Canada. We use the 2019-2020 waves of the CSCE which included several questions on working arrangements similar to those of the SWA.

\subsection{Definitions}

A key operational definition in this paper is that of a multiple jobholder. Multiple jobholders are respondents who hold more than one job during the reference week of the survey. ${ }^{9}$ The LFS collects information on hours on the respondent's main job and hours on all jobs for those who hold more than one job. The 'main job' (also called 'primary job') is determined by each respondent's own understanding of the term, and in all likelihood this is the job with the greatest number of hours worked. ${ }^{10}$ Another important definition of the analysis is that of part-time employment. In labour market statistics, whether a job is considered part-time or full-time depends on the number of hours usually worked at this job. We use a threshold of 30 usual hours to distinguish between part-time and full-time work. This threshold is standard in Canadian statistics and it does not drive our results. ${ }^{11}$

On the various plots of the paper, we will use gray bands to denote recession periods. To identify these episodes, we use the seasonally adjusted series of total hours worked normalized

\footnotetext{
${ }^{8}$ For information about the SWA, see https://www23.statcan.gc.ca/imdb/p2SV. pl?Function=getSurvey\&SDDS=3884. For information about the CSCE, see https: //www . bankof canada.ca/publications/canadian-survey-of-consumer-expectations/ canadian-survey-of-consumer-expectations-overview/.

${ }^{9}$ The reference week of the LFS is usually the week containing the 15 th of the month, and LFS interviews are conducted during the week that follows the reference week.

${ }^{10}$ In U.S. CPS data multiple jobholders report the number of jobs they hold in addition to reporting hours on the primary job and hours on all jobs. The vast majority of U.S. multiple jobholders (more than 90 percent) hold 'only' two jobs. Moreover, we observe that the difference between average hours on all jobs vs. on the primary job in the U.S. is roughly the same as that found in Canadian data. This suggests that most multiple jobholders in Canada do not hold more than two jobs.

${ }^{11}$ Results based on a 35-hours threshold to define part-time employment are available upon request.
} 
by the population of working age (i.e., the employment rate times average hours per employed worker). We define recessions as periods in which total hours worked decline by at least 3 percent, and define peaks (resp. troughs) as the first month during which hours start to drop (resp. recover). Based on these definitions, we obtain the following recession episodes: 1981m06-1983m01, 1989m08-1993m07 and 2008m02-2009m07. These dates are consistent with those determined by the C.D. Howe Institute Business Cycle Council ${ }^{12}$, while configuring longer recession episodes because of how we set business cycle peak and trough dates. The advantage is that our definition is directly focused on capturing slack in the labour market during economic downturns.

\section{Preliminary facts about multiple jobholding}

This section describes a set of preliminary facts about multiple jobholding. To set the stage, Figure 1 reports numbers of individuals who are not employed $(N)$, single jobholders $(S)$ or multiple jobholders $(M)$. The numbers are averages calculated over the last five years covered by the data. During this period, there are about 18 million individuals who are employed in a given month. Most of them are single jobholders, although multiple jobholders represent a fairly significant number (almost 1 million workers, or 5.75 percent of total employment). The employment rate at this time is at 61.4 percent and there are 11 million individuals who are not employed (i.e. unemployed or out of the labor force).

In Figure 1, we also display the average number of individuals who move between the $N$, $S$ and $M$ 'pools'. About 300 thousands employed workers (the sum of 161,984 and 143,102) switch between single and multiple jobholding between two consecutive months. The flow out of multiple jobholding is large when compared to the overall number of multiple jobholders: 14.4 percent, on average, return to single jobholding within each month. As one would expect,

\footnotetext{
${ }^{12}$ The C.D. Howe Institute Business Cycle Council performs functions similar to the Business Cycle Dating Committee of the National Bureau of Economic Research in the United States. The Council has identified the following recession episodes: 1981m06-1982m10, 1990m03-1992m05 and 2008m10-2009m05; see https: //www.cdhowe.org/council/business-cycle-council. A drawback of the Council's recession dates is that they miss a non-negligible share of the decline in total hours worked that took place at the onset of the two most recent recessions. According to the Council, total hours worked fell by 7.52 percent during the early-1990s recession and by 5.27 percent during the 2008-09 recession. In our own definition of recessions, these numbers are 9.54 percent and 6.94 percent, respectively.
} 


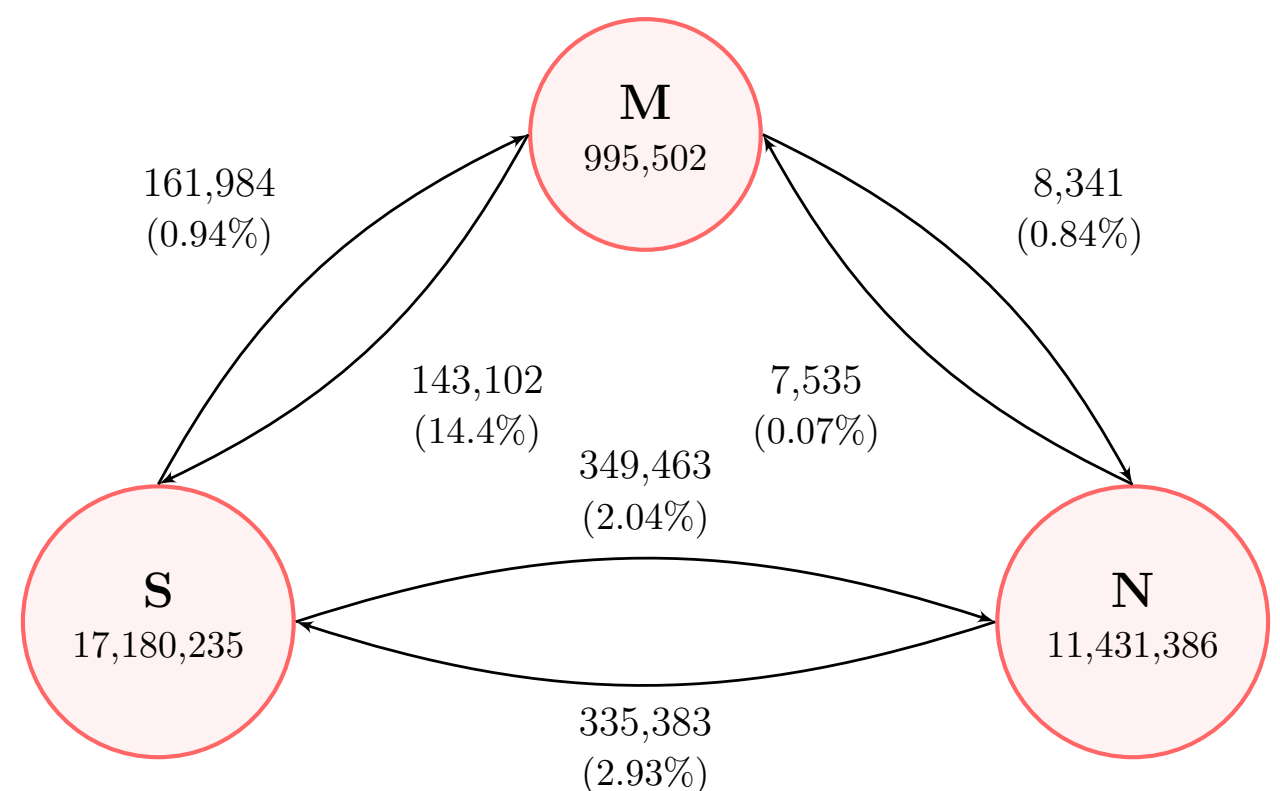

Figure 1: Worker flows across multiple jobholding, single jobholding and nonemployment

Notes: LFS data, 2014m01-2018m12. Figures inside the boxes: counts of multiple jobholders $(M)$, single jobholders $(S)$ and nonemployed individuals $(N)$. Figures next to the arrows: monthly worker flows. Figures in rounded brackets: transition probabilities (in percent). All figures refer to averages of time series over the period.

very few individuals who are not employed in a given month become multiple jobholders in the month that follows; the corresponding probability is 0.07 percent (after controlling for timeaggregation bias, as we explain in Section 4 and Appendix B). There are also few transitions directly from multiple jobholding to nonemployment. ${ }^{13}$

\subsection{Organizing framework}

To dig deeper into the dynamics of the worker flows represented in Figure 1, we set up the following framework. We classify workers into one of the following states: multiple jobholding with a full-time main job $\left(F_{M}\right)$, multiple jobholding with a part-time main job $\left(P_{M}\right)$, single jobholding with a full-time job $\left(F_{S}\right)$, single jobholding with a part-time job $\left(P_{S}\right)$, and nonem-

\footnotetext{
${ }^{13}$ Nonemployed workers become single jobholders with a monthly probability of 2.98 percent. This number might seem low, but note that it is a weighted average between the probability of moving to single jobholding from unemployment and from inactivity (which are lumped together into a single category that we call 'nonemployment'). The weights on these probabilities correspond to the shares of unemployed and inactive workers in the pool of nonemployment.
} 
ployment $(N)$. We let the vector $\boldsymbol{\ell}_{t}$ contain the number of individuals in each of these states:

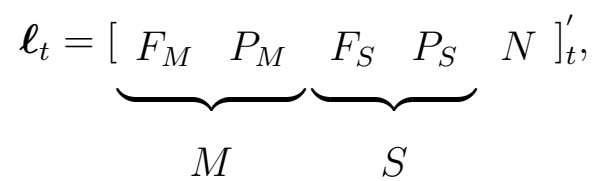

where $M=F_{M}+P_{M}$ (resp. $\left.S=F_{S}+P_{S}\right)$ is the number of multiple (resp. single) jobholders during month $t$. Our interest lies in understanding the behavior of the multiple jobholding share, which is the ratio between the number of multiple jobholders and the total number of employed individuals:

$$
m_{t}=\frac{F_{M, t}+P_{M, t}}{F_{M, t}+P_{M, t}+F_{S, t}+P_{S, t}} .
$$

Later on, we will relate the dynamics of the share $m_{t}$ to the worker flows represented by the arrows shown in Figure 1.

\subsection{A first look at the trends in multiple jobholding}

The solid line in Figure 2 are time series of the multiple jobholding share. In this figure and in the remainder of the analysis, instead of working with aggregate data, we present results separately by gender. We emphasize gender differences for mainly two reasons. One, the heterogeneity with respect to the incidence of part-time work (details follow). Two, the different timing of the change in multiple jobholding, which is evidenced in Figure 2. At the beginning of the sample period in 1976, men are more likely to be multiple jobholders $(2.6$ percent) than women (1.5 percent). The opposite is true in 2018: the multiple jobholding share is at 7.0 percent among women vs. 5.0 percent among men. The dynamics in between 1976 and 2018 are quite different. The increase in multiple jobholding throughout the 1980s is much steeper among women than among men. Then, during the 1990s, multiple jobholding plateaus for men whereas it continues to increase for women, albeit at a slower rate compared to the 1980s. The multiple jobholding share among men resumes its increase after the turn of the century. On the other hand, the upward trend for women in the 2000s and 2010s is no different from that in the 1990s. Motivated by these observations, in the next two sections we split the sample period into three subperiods: 1976-1990, 1990-2000, and 2000-2018 in order to provide 


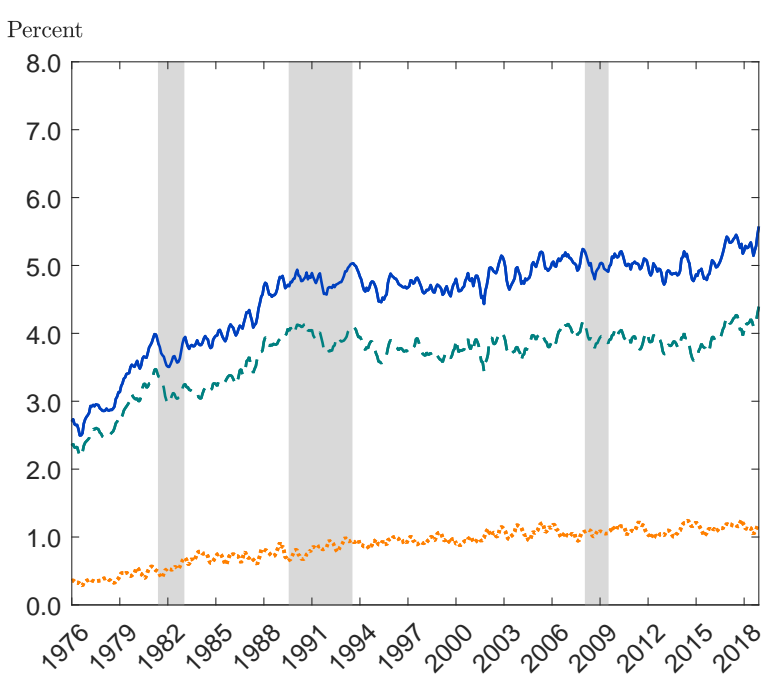

(a) Men

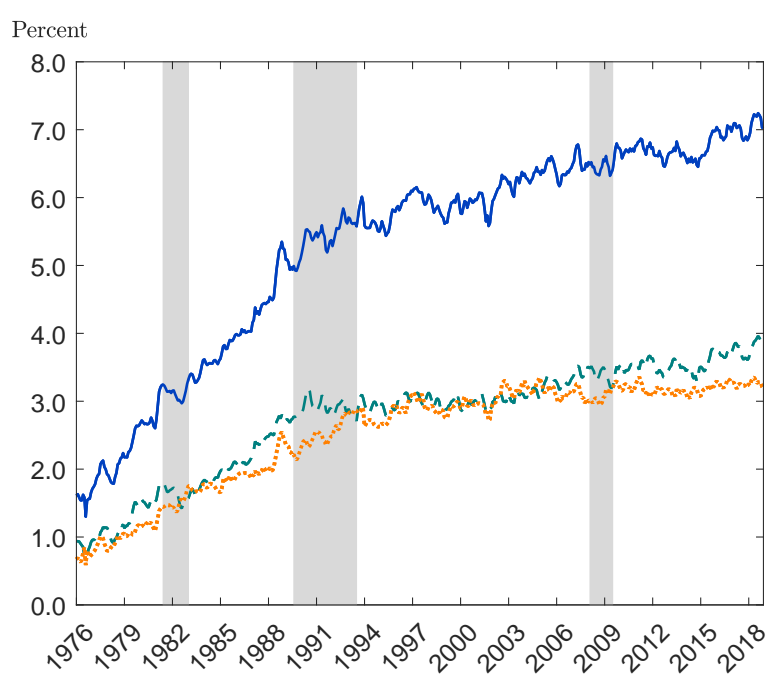

(b) Women

$$
-m_{t} \quad---\frac{F_{M, t}}{F_{M, t}+P_{M, t}+F_{S, t}+P_{S, t}} \quad \cdots \cdots \cdots \cdots \cdot \frac{P_{M, t}}{F_{M, t}+P_{M, t}+F_{S, t}+P_{S, t}}
$$

Figure 2: Full-time and part-time multiple jobholding among men and women: 1976-2018

Notes: LFS data, 1976m01 - 2018m12. Solid lines: multiple jobholders as a share (in percent) of all employed individuals. Dashed (dotted) lines: Multiple jobholders working full-time (parttime) on their main job as a share (in percent) of all employed individuals. All time series are seasonally adjusted. Gray-shaded areas indicate recession periods.

a clearer picture of the changes that took place over time. ${ }^{14}$

In Figure 2, we also plot two components of the multiple jobholding share:

$$
\frac{F_{M, t}}{F_{M, t}+P_{M, t}+F_{S, t}+P_{S, t}} \text { and } \frac{P_{M, t}}{F_{M, t}+P_{M, t}+F_{S, t}+P_{S, t}}
$$

measuring the full-time and part-time multiple jobholding shares, respectively. As can be seen, the underlying composition of multiple jobholding is very different across gender: the majority of men with multiple jobs work full-time on the main job, while for women there is a more even split between full-time and part-time hours of the main job. There is also a difference between men and women concerning the evolution over time shown in Figure 2. For women, the increase in the multiple jobholding share is coming from both the full-time and

\footnotetext{
${ }^{14}$ We also implemented a more systematic approach to check whether potential breaks in the time series of multiple jobholding could be detected. We regress the time series $m_{t}$ against a time trend and test whether the coefficients of this regression change over the periods defined by an unknown break date. This allows us to construct a Wald-type statistic, the values of which increase at potential break dates. The Wald statistic exceeds 100 in and around the years 1980 and 2000, and it exceeds 300 in and around 1990. These upward shifts confirm our choice our break-up points in 1990 and 2000. We leave aside the break-up point of 1980 because we would have too few data points to analyze for the pre-1980 period.
} 
Table 1: Multiple jobholding and part-time employment shares

\begin{tabular}{|c|cc|cccccc|}
\hline \hline & \multicolumn{2}{|c|}{$1976-2018$} & \multicolumn{2}{c}{$1976-1990$} & \multicolumn{2}{c|}{ 1990-2000 } & \multicolumn{2}{c|}{ 2000-2018 } \\
Men & Level & Growth & Level & Growth & Level & Growth & Level & Growth \\
\hline$m_{t}$ & 4.53 & 1.75 & 3.82 & 4.52 & 4.73 & -0.02 & 4.99 & 0.73 \\
$\frac{P_{M, t}}{F_{M, t}+P_{M, t}}$ & 18.9 & 1.44 & 15.1 & 1.69 & 19.2 & 2.13 & 21.6 & 0.17 \\
$\frac{P_{S, t}}{F_{S, t}+P_{S, t}}$ & 10.1 & 1.69 & 8.08 & 3.21 & 10.5 & 1.20 & 11.5 & 0.95 \\
\hline Women & \multicolumn{2}{|c|}{$1976-2018$} & \multicolumn{2}{|c|}{$1976-1990$} & \multicolumn{2}{c}{$1990-2000$} & \multicolumn{2}{c}{$2000-2018$} \\
Wevel & Growth & Level & Growth & Level & Growth & Level & Growth \\
\hline$m_{t}$ & 5.27 & 3.84 & 3.41 & 9.47 & 5.72 & 1.54 & 6.52 & 1.06 \\
$\frac{P_{M, t}}{F_{M, t}+P_{M, t}}$ & 47.7 & 0.07 & 46.4 & -0.07 & 48.4 & 1.05 & 48.2 & -0.35 \\
$\frac{P_{S, t}+P_{S, t}}{F_{S, t}+P_{S}}$ & 27.3 & 0.24 & 26.6 & 0.80 & 27.9 & 0.36 & 27.5 & -0.15 \\
\hline \hline
\end{tabular}

Notes: LFS data, 1976m01 - 2018m12. $m_{t}$ : multiple jobholding share; $F_{S}$ : single jobholding with a fulltime job; $P_{S}$ : single jobholding with a part-time job; $F_{M}$ : multiple jobholding working full-time on the main job; $P_{M}$ : multiple jobholding working part-time on the main job. The table reports average levels ('Level') and average yearly growth rates ('Growth') over the sample period and over specific subperiods. All table entries are expressed in percent.

part-time multiple jobholding shares, implying that the composition of multiple jobholding remains unchanged over time. For men on the other hand, the full-time multiple jobholding share is roughly constant during the 1990s while the part-time multiple jobholding share keeps increasing after the recession of the early 1990s up until the end of the 2010s. As a result, the composition of multiple jobholding shifts towards men who work part-time on the main job.

Table 1 complements Figure 2 by summarizing the evolution of the multiple jobholding share and of two ratios, namely the share of multiple jobholders who are employed part-time on the main job $\left(\frac{P_{M, t}}{F_{M, t}+P_{M, t}}\right)$ and the share of part-time workers among single jobholders $\left(\frac{P_{S, t}}{F_{S, t}+P_{S, t}}\right)$. First, the table reiterates that men and women's multiple jobholding shares, $m_{t}$, have behaved differently over time. In particular, the growth rate in multiple jobholding is twice larger for women than for men over the whole sample period. Second, the table highlights differences in the incidence of part-time employment across the two gender groups. Men are less likely to work part-time than women when they hold two jobs (18.9 percent vs. 47.7 percent), and even more so when they work only one job (10.1 percent for men vs. 27.3 percent for women). Meanwhile, the incidence of part-time work increases over time among male multiple jobholders $\left(\frac{P_{M, t}}{F_{M, t}+P_{M, t}}\right)$ : the average share of multiple jobholders with a part-time main job is raised by 50 percent from the first to the third subperiod. The incidence of part-time work among male single jobholders $\left(\frac{P_{S, t}}{F_{S, t}+P_{S, t}}\right)$ increases more modestly. Third, as we noticed with Figure 2, the 
composition of women's employment pool appears to be more stable than that of men. The most noticeable shift is the 1990-2000 change in the composition of multiple jobholding towards women who hold a part-time main job, but it is small in quantitative terms. Fourth, while the majority of multiple jobholders are working full-time on their main job and adding more hours by holding a second job, there is a significant degree of heterogeneity between men and women regarding this pattern. 71.1 percent of male multiple jobholders hold a full-time main job while the corresponding figure for female multiple jobholders is 52.3 percent.

\subsection{Individual characteristics of multiple jobholders}

We continue our preliminary analysis by looking at the relationships between multiple jobholding and a set of socio-demographic characteristics (age, education, marital status, region of residence) and industry of employment. Descriptive statistics are presented in Table 2. A number of patterns are readily visible. First, multiple jobholding is negatively related to age. This is not surprising insofar as economic reasons (buying something special, paying off debt, etc.) and human capital motives (gaining experience) play major roles in the decision to take on a second job, as we discuss in Section 6. Second, the levels of multiple jobholding vary significantly by educational levels and are substantially higher among more educated workers. Similar patterns have been documented in data for the United States. Third, there are also substantial variations related to the worker's primary industry of employment. For instance, multiple jobholding is more common among workers employed in education and health services. It is likely that the gradients in terms of education and industry are related to each other. Again, these patterns are consistent with findings for the United States. For example Lalé [2016] notes that multiple jobholding is quite common among teachers in elementary, middle, or secondary schools, whose multiple jobholding shares can be as high as 13 percent. Fourth, Table 2 shows similar relationships between multiple jobholding and individual characteristics in the two gender groups.

In Table 2, we also report the (average yearly) growth rate of the multiple jobholding share within each population subgroup. The purpose is to compare it to the overall growth of men's and women's multiple jobholding shares displayed in the first row of Table 2. First, 
Table 2: The multiple jobholding share within socio-demographic and industry subgroups

\begin{tabular}{|l|cc|cc|}
\hline \hline & \multicolumn{2}{|c|}{ Men: } & \multicolumn{2}{c|}{ Women: } \\
& Level & Growth & Level & Growth \\
\hline All: & 4.53 & 1.75 & 5.27 & 3.84 \\
Age: & & & & \\
15-24 years & 4.53 & 2.37 & 6.66 & 4.05 \\
25-34 years & 4.47 & 1.58 & 5.35 & 3.79 \\
35-44 years & 4.47 & 1.32 & 5.01 & 3.46 \\
45-54 years & 4.00 & 1.58 & 4.60 & 3.82 \\
55 years and above & 3.35 & 2.11 & 3.59 & 4.38 \\
Education: & & & & \\
0-8 years & 2.81 & 1.16 & 2.41 & 4.08 \\
Secondary school & 3.79 & 1.48 & 4.56 & 3.42 \\
Some post secondary education & 4.47 & 1.31 & 5.72 & 3.30 \\
University degree & 5.21 & 1.70 & 5.91 & 2.73 \\
Marital status: & & & & \\
Married or cohabiting & 4.17 & 1.44 & 4.54 & 3.41 \\
Widowed, divorced or separated & 4.02 & 2.58 & 5.49 & 3.73 \\
Never married & 4.29 & 2.19 & 6.31 & 3.94 \\
Industry: & & & & \\
Agriculture & 7.18 & 0.60 & 7.19 & 2.62 \\
Mining, oil, gas, and utilities & 2.94 & 1.44 & 3.16 & 5.24 \\
Construction & 2.83 & 1.52 & 5.38 & 4.60 \\
Manufacturing & 2.76 & 1.54 & 2.59 & 4.18 \\
Transportation & 3.57 & 1.53 & 5.19 & 2.26 \\
Wholesale trade & 3.88 & 2.41 & 3.89 & 4.56 \\
Retail trade & 4.06 & 2.24 & 4.91 & 3.45 \\
Finance, insurance, real estate & 4.08 & 2.68 & 3.71 & 3.66 \\
Professional, technical & 4.31 & 2.73 & 5.03 & 3.85 \\
$\quad$ and management services & 7.71 & 1.86 & 6.30 & 4.48 \\
Educational and health services & 4.95 & 2.21 & 5.62 & 3.44 \\
Recreation, accommodation & 4.68 & 2.16 & 3.80 & 3.53 \\
$\quad$ and food services & & & & \\
Public administration & 3.33 & 1.41 & 3.99 & 4.00 \\
Region and CMA $\left.{ }^{*}\right):$ & 3.27 & 2.05 & 3.55 & 5.37 \\
Atlantic & 3.69 & 0.76 & 3.80 & 3.21 \\
Québec, excl. Montréal & 4.41 & 1.64 & 5.60 & 3.33 \\
Montréal QC & 3.84 & 1.83 & 4.95 & 3.49 \\
Ontario, excl. Toronto & 5.74 & 0.95 & 7.18 & 2.83 \\
Toronto ON & 4.49 & 2.61 & 6.45 & 4.02 \\
Prairie provinces & 4.47 & 1.63 & 6.03 & 2.21 \\
British Columbia, excl. Vancouver \\
Vancouver BC & & & & \\
\hline \hline
\end{tabular}

Notes: LFS data, 1976m01 - 2018m12. (*): The Census metropolitan area (CMA) data is available only starting in 1987. The table reports average levels ('Level') and average yearly growth rates ('Growth') over the sample period of the multiple jobholding share within different population subgroups. All table entries are expressed in percent. 
we observe that multiple jobholding has increased within all age, education, marital status, industry and region subgroups. Second, the fact that multiple jobholding has increased more for women than for men holds true within almost all population subgroups. Third, there is some heterogeneity in growth rates across subgroups. For instance, multiple jobholding shares have grown faster among younger and older workers than among workers aged 25 to 54 . This begs the question of whether the trends reported in the first row of Table 2 are driven by composition effects, i.e. shifts in the shares of population groups that experienced the largest increases in multiple jobholding. To answer this question, we perform the following exercise (details are provided in Appendix C). We compute counterfactual multiple jobholding shares cleared from changes in the shares of each population subgroups, and we compare them to men's and women's actual multiple jobholding shares. The outcome of this exercise is readily described. The counterfactual are very similar to the actual multiple jobholding shares, showing that composition effects play virtually no role in the dynamics of men's and women's multiple jobholding shares. In sum, the data split by gender without further disaggregation captures well the interesting patterns of the dynamics of multiple jobholding over the sample period.

\section{The ins and outs of multiple jobholding}

Having described the 'pools' of male and female multiple jobholders, we turn our attention to the transition probabilities of entering and leaving these pools. As is standard, we assume that the evolution of $\boldsymbol{\ell}_{t}$ (equation (1)) is governed by a first-order Markov chain:

$$
\ell_{t}=\boldsymbol{X}_{t} \ell_{t-1}
$$

In this equation, $\boldsymbol{X}_{t}$ is the stochastic matrix of transition probabilities $p(i \rightarrow j)$ across labour market states $i$ and $j$. Each of these transition probabilities is measured by the gross flow of workers from state $i$ to state $j$ in month $t$ divided by the stock, or number, of workers in state $i$ in month $t-1$.

We implement several adjustments based on the Markov chain structure of this framework. ${ }^{15}$

\footnotetext{
${ }^{15}$ Prior to making these adjustments, we remove systematic seasonal variations using the U.S. Census Bu-
} 
First, we perform a margin-error adjustment (also called 'raking') of the transition probabilities (Poterba and Summers [1986], Elsby et al. [2015]). This adjustment reconciles the changes in stocks predicted by the Markov chain with the actual changes in stocks that occur between two consecutive months. These are different because the former are derived from worker flows computed from longitudinally-linked data, which are affected by rotational sample attrition, whereas the actual changes in stocks are only based on cross-sectional data. Second, we correct transition probabilities to account for time-aggregation bias. Time-aggregation bias refers to the discrepancy between the transition probabilities measured at discrete intervals and the underlying continuous process which they seek to measure. Specifically, the competing risks structure of the process implies that the discrete-time (monthly) probabilities miss some of the transitions that occur at a higher frequency. We adapt Shimer [2012]'s continuous-time correction to our setup to address this bias. We refer the reader to Appendix B for a more formal presentation of the adjustment procedures.

Long-run averages. Table 3 describes the dynamics of multiple jobholding through its interaction with other labour market states. Specifically, each panel of Table 3 reports the averages of inflow and outflow transition probabilities. ${ }^{16}$ The bottom row of each panel displays the sum of the inflow (resp. outflow) transition probabilities whose states of origin (resp. destination) exclude multiple jobholding. Three results stand out. The first one is that multiple jobholding is a transitory state of employment. When looking at individuals with a full-time main job $\left(F_{M}\right)$, about one sixth (14.0 percent for men, 16.5 percent for women) were in a different state in the previous month and a similarly large share leaves in the following month (13.9 percent for men, 16.7 percent for women). The figures are higher for multiple jobholders who work part-time on the main job $\left(P_{M}\right)$. In expected terms (under the assumption of a constant outflow rate), these figures imply that a spell of multiple jobholding in full-time work lasts on average 7.2 months $(=1 / 0.139$ months $)$ for men and 6.0 months for women. The corresponding figures for multiple jobholding with a part-time primary job are 5.0 months

reau's X-13ARIMA-SEATS program (https : / www. census.gov/srd/www/x13as/).

${ }^{16} q(i \rightarrow j)$ denotes the inflow transition probability from state $i$ to $j$. It is the ratio of the gross flow from state $i$ to $j$ between months $t-1$ and $t$ over the stock of workers in state $j$ in month $t$. The outflow transition probabilities are the elements of the Markov transition matrix from equation (4). 


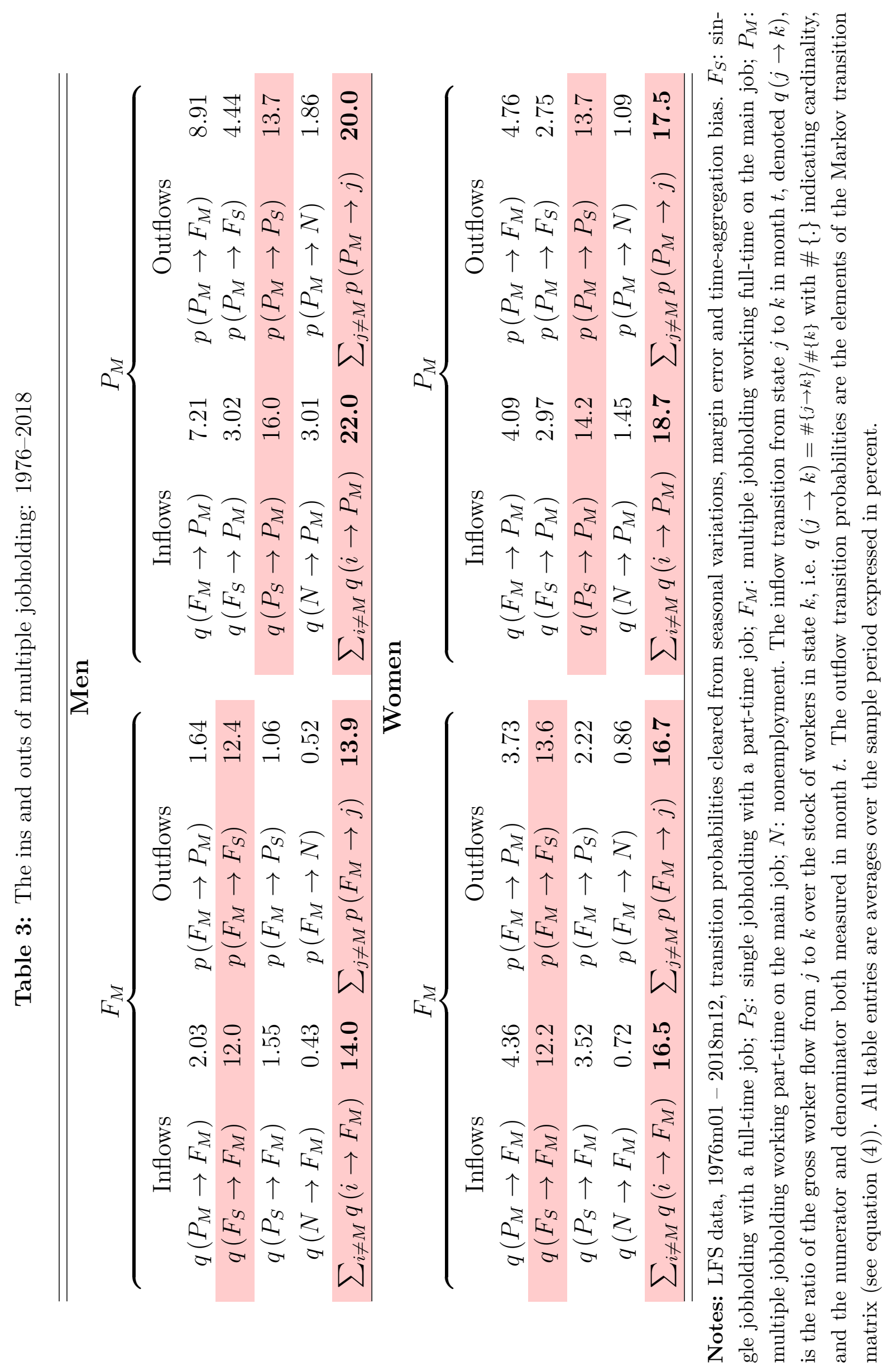


for men and 5.7 months for women. Second, there is a non-negligible share of workers who change status with respect to their primary job upon moving into or out of multiple jobholding. This holds true especially for multiple jobholders with a part-time primary job during the reference week $\left(P_{M}\right)$ : the probability that they hold a single full-time job $\left(F_{S}\right)$ in the previous month or during the month that follows is between 2.75 and 4.44 percent. Third, transitions between multiple jobholding and nonemployment $(N)$ are mostly negligible. Thus, although our vector $\boldsymbol{\ell}_{t}$ lumps together unemployed and inactive workers, whose behavior when they return to employment might be quite different, this should have little impact on our study of transitions in and out of multiple jobholding.

Dynamic behavior. Figures 3 and 4 complement Table 3 by displaying the transition probabilities of moving in and out of multiple jobholding. There are two displayed time series in each plot, except for the plots at the bottom showing a transition to or from nonemployment $(N)$. For instance, in Figure 3 in the top left panel, the dashed line is the probability that a full-time single jobholder $\left(F_{S}\right)$ takes on a second job while holding onto a full-time primary work schedule $\left(F_{M}\right)$. The solid line on the same plot denotes the overall probability that this worker becomes a multiple jobholder, viz. s/he moves to either $F_{M}$ or $P_{M}$. Clearly, in each plot, the transition probability denoted by the dashed line is the main component of the transition probability denoted by the solid line.

A first pattern worthy of attention in Figure 3 is that transitions from both full-time $\left(F_{S}\right)$ and part-time $\left(P_{S}\right)$ single jobholding have become more frequent over time. This pattern is especially important for female multiple jobholders, whose probabilities to take on a second job have more than doubled since the mid-1970s (their $p\left(F_{S} \rightarrow M\right)$ increases from 0.35 percent in 1976 to 0.77 percent in 2018, and $p\left(P_{S} \rightarrow M\right)$ from 0.61 to 2.28 percent). An increase in the inflow transition probability implies ceteris paribus an increase in the number of multiple jobholders. In other words, Figure 3 offers a first candidate explanation for the upward trends shown in Figure 2: single jobholders have become more likely to take on second jobs. Of course, the figure itself does not tell us how important the effect is. The other pattern evidenced in Figure 3 is the pro-cyclicality of the inflow transition probabilities of multiple jobholding. During recessions, single jobholders are less likely to take on a second job. The recessionary 

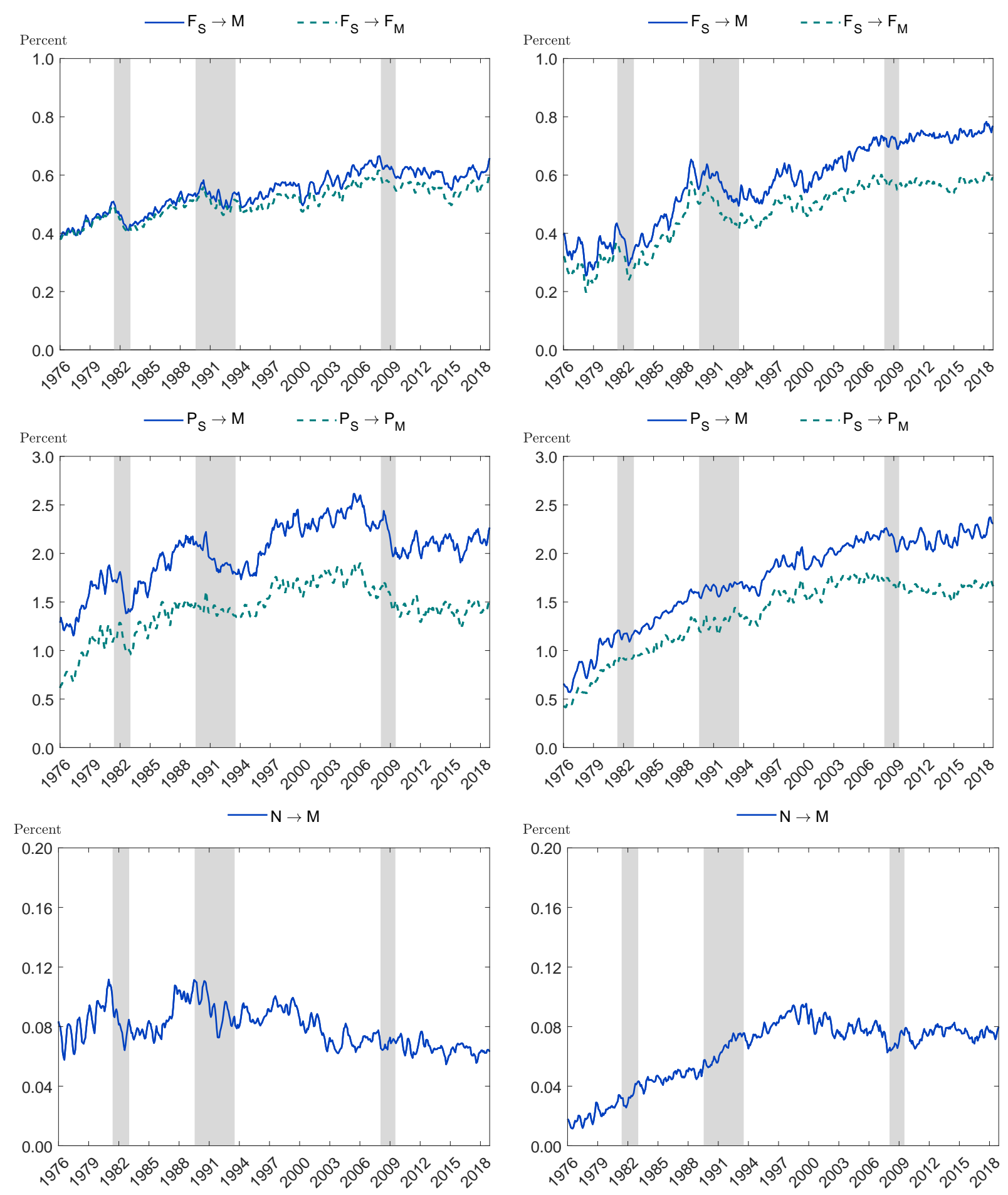

(a) Men

(b) Women

Figure 3: Transition probabilities into multiple jobholding: 1976-2018

Notes: LFS data, 1976m01 - 2018m12. Solid and dashed lines: transition probabilities cleared from margin error and time-aggregation bias (see Section 4 and Appendix B for details). All time series are seasonally adjusted and smoothed by one-month, two-sided MA averaging. Gray-shaded areas indicate recession periods. 

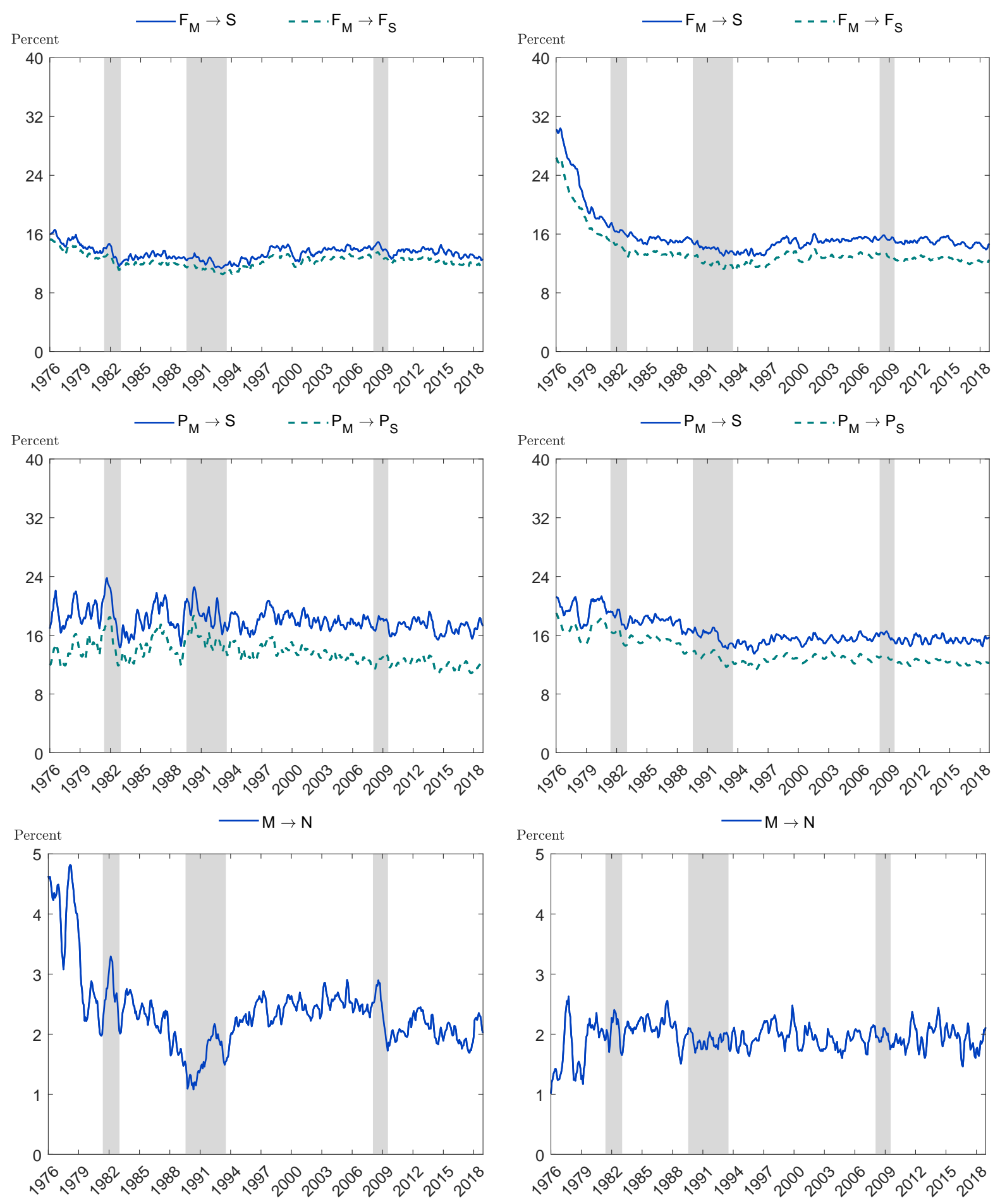

(a) Men

(b) Women

Figure 4: Transition probabilities out of multiple jobholding: 1976-2018

Notes: LFS data, 1976m01 - 2018m12. Solid and dashed lines: transition probabilities cleared from margin error and time-aggregation bias (see Section 4 and Appendix B for details). All time series are seasonally adjusted and smoothed by one-month, two-sided MA averaging. Gray-shaded areas indicate recession periods. 
drop is very pronounced for men during all three downturns. For women, we see a decrease in $p\left(F_{S} \rightarrow M\right)$ during the first two recessions, but not during the 2008-09 recession. Also, the business-cycle patterns are much attenuated among part-time working women (based on the behavior of $p\left(P_{S} \rightarrow M\right)$ during downturns $)$. We will return to these cyclical patterns in Section 5 below.

Next, we turn our attention to the plots in Figure 4 showing the probability to give up the second job. This probability has shifted downwards among multiple jobholders with either a full-time $\left(F_{M}\right)$ or part-time $\left(P_{M}\right)$ main job. The decline is especially large at the beginning of the sample period. Holding the inflow rate constant over time, this pattern implies an increase in the number of multiple jobholders. Thus, we have another candidate explanation of the trends in multiple jobholding, namely that multiple jobholders have become less likely to give up the second job. Figure 4 also reveals some cyclicality in the outflow transition probability, at least for male workers whose $p\left(F_{M} \rightarrow S\right)$ and $p\left(P_{M} \rightarrow S\right)$ drop during recessions. For women, again, cyclical movements are less pronounced. Finally, let us comment on the very large drop in women's transition probability $p\left(F_{M} \rightarrow S\right)$ at the beginning of the sample period. Recall that a transition probability is a ratio between worker flows and stocks. In the 1970s, there are very few women holding multiple jobs. As a result, the composition of the pool of female multiple jobholders (the stock) and that of the outflow can be very sensitive to changes in the type of women who move into multiple jobholding. It is conceivable, for instance, that the flow into multiple jobholding in the 1970s shifts towards female workers who are prone to longer spells of multiple jobholding (e.g., women who supply more hours to the labour market), and that this compositional in turn lowers the outflow transition probability. In line with this hypothesis, in calculations not reported here, we find that short-term (1 month) spells as a share of women's overall spells of multiple jobholding fall throughout the 1970s and 1980s.

\section{$5 \quad$ Dissecting the dynamics of multiple jobholding}

Figures 3 and 4 show that transition probabilities in and out of second jobs have moved in diverse directions over time, necessitating close scrutiny to understand the trends in men's and 
women's multiple jobholding shares. In this section, we develop a measurement framework that quantifies their contribution to the dynamics of multiple jobholding. By applying this decomposition period by period, we can narrow down the picture to the most relevant source of variation of the multiple jobholding share.

\subsection{A trend decomposition}

We follow a common practice in the 'ins and outs' literature: we focus on so-called 'steadystate' approximations to quantify the role played by the dynamics of the different transition probabilities. The steady-state multiple jobholding share in month $t$, denoted as $\bar{m}_{t}$, is the share implied by the contemporaneous values of the flow hazards, which we define momentarily. The reason why $\bar{m}_{t}$ provides a good approximation to the actual multiple jobholding share is that convergence towards the steady state is nearly completed within each month due to the high levels of transitions across labour market states. As will be shown below, the steady-state and actual multiple jobholding shares do track each other closely.

To make the relationship between $\bar{m}_{t}$ and the transition probabilities explicit, we start by rewriting the Markov chain of equation (4) as

$$
\widetilde{\ell}_{t}=\widetilde{\boldsymbol{X}}_{t} \widetilde{\ell}_{t-1}+\mathbf{x}_{\mathbf{t}}
$$

Here we denote by $\widetilde{\boldsymbol{\ell}}_{t}$ the vector $\boldsymbol{\ell}_{t}$ normalized by the size of the population aged 15 and above $\left(F_{M, t}+P_{M, t}+F_{S, t}+P_{S, t}+N_{t}\right)$, and by $\widetilde{\boldsymbol{X}}_{t}$ the matrix $\boldsymbol{X}_{t}$ rearranged accordingly. Hence, the vector $\mathbf{x}_{\mathbf{t}}$ is: $\left[\begin{array}{llll}p\left(N \rightarrow F_{M}\right) & p\left(N \rightarrow P_{M}\right) & p\left(N \rightarrow F_{S}\right) & p\left(N \rightarrow P_{S}\right)\end{array}\right]_{t}^{\prime}$. It is then possible to define the continuous-time counterpart of equation (5):

$$
\dot{\widetilde{\ell}}_{t}=\widetilde{\boldsymbol{H}}_{t} \widetilde{\ell}_{t}+\mathbf{h}_{\mathbf{t}}
$$

In this equation, the elements of $\widetilde{\boldsymbol{H}}_{t}$ and $\mathbf{h}_{t}$ are flow hazards, the continuous-time counterparts of the discrete-time transition probabilities. ${ }^{17} \lambda^{i j}$ denotes the flow hazard from state $i$ to state

\footnotetext{
${ }^{17}$ The upper dot on $\widetilde{\ell}_{t}$ in the left-hand side of equation (6) denotes its first-order time derivative. Notice that on the right-hand side of this equation, $\widetilde{\boldsymbol{H}}_{t}$ multiplies the month- $t$ vector $\widetilde{\boldsymbol{\ell}}_{t}$ whereas $\widetilde{\boldsymbol{X}}_{t}$ multiplies the vector of stocks from month $t-1$ in equation (5).
} 
$j ; \lambda^{i j}$ can be computed using the relationship: $p(i \rightarrow j)=1-e^{-\lambda^{i j}}$. To illustrate the role of flow hazards, let us write equation (6) in explicit form:

$$
\begin{aligned}
& {\left[\begin{array}{c}
\dot{\widetilde{F}}_{M} \\
\dot{\widetilde{P}}_{M} \\
\dot{\widetilde{F}}_{S} \\
\dot{\widetilde{P}}_{S}
\end{array}\right]_{t}\left[\begin{array}{cccc}
-\sum_{j \neq F_{M}} \lambda^{F_{M} j}-\lambda^{N F_{M}} & \lambda^{P_{M} F_{M}}-\lambda^{N F_{M}} & \lambda^{F_{S} F_{M}}-\lambda^{N F_{M}} & \lambda^{P_{S} F_{M}}-\lambda^{N F_{M}} \\
\lambda^{F_{M} P_{M}}-\lambda^{N P_{M}} & -\sum_{j \neq P_{M}} \lambda^{P_{M} j}-\lambda^{N P_{M}} & \lambda^{F_{S} P_{M}}-\lambda^{N P_{M}} & \lambda^{P_{S} P_{M}}-\lambda^{N P_{M}} \\
\lambda^{F_{M} F_{S}}-\lambda^{N F_{S}} & \lambda^{P_{M} F_{S}}-\lambda^{N F_{S}} & -\sum_{j \neq F_{S}} \lambda^{F_{S} j}-\lambda^{N F_{S}} & \lambda^{P_{S} F_{S}}-\lambda^{N F_{S}} \\
\lambda^{F_{M} P_{S}}-\lambda^{N P_{S}} & \lambda^{P_{M} P_{S}}-\lambda^{N P_{S}} & \lambda^{F_{S} P_{S}}-\lambda^{N P_{S}} & -\sum_{j \neq P_{S}} \lambda^{P_{S} j}-\lambda^{N P_{S}}
\end{array}\right]_{t}} \\
& \times\left[\begin{array}{c}
\widetilde{F}_{M} \\
\widetilde{P}_{M} \\
\widetilde{F}_{S} \\
\widetilde{P}_{S}
\end{array}\right]_{t}+\left[\begin{array}{c}
\lambda^{N F_{M}} \\
\lambda^{N P_{M}} \\
\lambda^{N F_{S}} \\
\lambda^{N P_{S}}
\end{array}\right]_{t}
\end{aligned}
$$

At the steady state, equation (6) yields the following relationship between the stocks in vector $\widetilde{\ell}_{t}$ and the underlying flow hazards:

$$
\overline{\widetilde{\ell}}_{t}=-\widetilde{\boldsymbol{H}}_{t}^{-1} \mathbf{h}_{t}
$$

One can then approximate each steady-state stock at time $t$, say $\overline{\widetilde{\ell}}_{t}$, with a Taylor expansion:

$$
\overline{\widetilde{\ell}}_{t}-\overline{\widetilde{\ell}} \approx \sum_{i \neq j} \frac{\partial \overline{\widetilde{\ell}}_{t}}{\partial \lambda^{i j}}\left(\lambda_{t}^{i j}-\lambda^{i j}\right)
$$

The notations without the time subscript $t$ denote the mean of a variable and $\frac{\partial \tilde{\tilde{\ell}}_{t}}{\partial \lambda^{i j}}$ are partial derivatives. The last step is to relate the deviation of stocks from their respective mean to the evolution of the steady-state multiple jobholding share. By totally differentiating the steadystate counterpart of equation (2), we have:

$$
d \bar{m}_{t}=\frac{\left(d \bar{F}_{M, t}+d \bar{P}_{M, t}\right)\left(1-\bar{m}_{t}\right)-\left(d \bar{F}_{S, t}+d \bar{P}_{S, t}\right) \bar{m}_{t}}{\bar{F}_{M, t}+\bar{P}_{M, t}+\bar{F}_{S, t}+\bar{P}_{S, t}}
$$

where the letter $d$ denotes the deviation of a stock from its mean. Then, we can combine 
equations (9) and (10) to construct counterfactual changes in the multiple jobholding share driven by changes in each flow hazard. Also, owing to the linearity of equation (9), we can construct counterfactual changes driven by changes in a group of flow hazards (e.g. the inflows, the outflows, etc.) by simply adding the individual counterfactual time series.

\subsection{Understanding period-by-period changes}

We use the framework developed in the previous subsection to understand the trends (or the lack thereof) of men's and women's multiple jobholding share over subperiods 1976-1990, 1990-2000, and 2000-2018. Specifically, for each subperiod beginning in period $t_{0}$ and ending in $t_{1}$, we use equation (10) to compute various counterfactual changes, $D \bar{m}$, defined by:

$$
D \bar{m}=\sum_{\tau=t_{0}}^{t_{1}} d \bar{m}_{\tau} .
$$

As we have already noted, we can compute the counterfactuals driven by a specific flow hazard or by a group of flow hazards.

The results of our trend decomposition are displayed in Table 4. To illustrate how the table works, let us describe the entries of the column labeled '1976-1990' in the panel for men. Between 1976 and 1990, the evolution of the transition probability $p\left(F_{S} \rightarrow M\right)$ per se implies an increase in men's multiple jobholding share by 0.83 percentage points (pp.). The corresponding figure for $p\left(P_{S} \rightarrow M\right)$ is $0.30 \mathrm{pp}$, and the figure for $p(N \rightarrow M)$ is $0.12 \mathrm{pp}$. Taken together, the inflow probabilities $\left(F_{S} \rightarrow M, P_{S} \rightarrow M\right.$ and $\left.N \rightarrow M\right)$ raise the multiple jobholding share by $1.26 \mathrm{pp}$. On the other hand, the predicted change based on the behavior of $p\left(F_{M} \rightarrow S\right)$ is a decrease by 0.11 pp., while $p\left(P_{M} \rightarrow S\right)$ generates an increase by $0.49 \mathrm{pp}$. and $p(M \rightarrow N)$ an increase by $0.08 \mathrm{pp}$. The cumulative effect of the outflow probabilities on the multiple jobholding share is an increase by $0.46 \mathrm{pp}$. Next, we add up the changes implied by the inflow and outflow transition probabilities. Together they result in a change of the multiple jobholding share by $1.72 \mathrm{pp}$. The other flows $\left(F_{S} \rightarrow P_{S}, F_{S} \rightarrow N\right.$, etc. $)$ might also shift the multiple jobholding share. The sum of their contribution is displayed in the row labeled 'Other flows'. During the period from 1976 to 1990, they raise men's multiple jobholding share by 0.08 
pp. Thus, the contributions of direct and indirect flows predict that the multiple jobholding share increases by $1.79 \mathrm{pp}$. This is very close to the change of the actual multiple jobholding share during this period, namely $1.76 \mathrm{pp}$. (last row of each panel in Table 4).

The first remark about Table 4 concerns the fit of the counterfactual time series. As can be seen at the bottom of each panel, the changes based on the behavior of the inflows and outflows capture the differences in the size of long-run changes between men and women, which we highlighted in Subsection 3.2, as well as its timing. That is, the increase of multiple jobholding is more pronounced among women than among men, is very large during the first subperiod, and is interrupted for men during the period going from 1990 to 2000 . Next, we note that, with exception of the intermediary subperiod for men, the inflow transition probabilities always contribute to raising the multiple jobholding share. The outflow transition probabilities, on the other hand, increase the multiple jobholding share in the first two but not in the third subperiod (the period from 2000 to 2018). During the 1990s, their effect is entirely offset by the negative contribution of the inflow transition probabilities among men. Indeed, the outflows would have raised men's multiple jobholding share by $0.07 \mathrm{pp}$., but multiple jobholding actually decreased because of the dynamics of the inflows. For women during the 1990-2000 subperiod, the contribution of the outflow transition probabilities is almost as large as that of the inflows, in contrast with the other two subperiods.

We now analyze Table 4 separately by gender. For men, the bulk of the increase (more than 70 percent) in multiple jobholding between 1976 and 1990 is explained by the inflows: they account for a $1.26 \mathrm{pp}$. increase out of the predicted $1.79 \mathrm{pp}$. change. During the second subperiod, the inflows even overpredict the change of the multiple jobholding share. They predict a decrease by -0.22 pp. vs. -0.06 when we sum up the contribution of all flows. By and large, in all three subperiods changes in the likelihood of single jobholders to take on second jobs is the main driver of men's multiple jobholding share. For women during the first subperiod, there is a $2 / 3-1 / 3$ split between the inflow and outflow contributions: the inflows raise the multiple jobholding share by $2.40 \mathrm{pp}$., which is two thirds of the $3.74 \mathrm{pp}$. increase coming from the inflow and outflow sum. During the 1990s, we observe a similar split between inflows and outflows, while between 2000 and 2018 the dynamics is entirely explained by the 
Table 4: Counterfactual changes in the multiple jobholding share

\begin{tabular}{|c|ccc|}
\hline \hline Men & $1976-1990$ & $1990-2000$ & $2000-2018$ \\
\hline$D \bar{m}\left(F_{S} \rightarrow M\right)$ & 0.83 & -0.22 & 0.54 \\
$D \bar{m}\left(P_{S} \rightarrow M\right)$ & 0.30 & 0.07 & -0.02 \\
$D \bar{m}(N \rightarrow M)$ & 0.12 & -0.06 & -0.05 \\
Sum of inflows & 1.26 & -0.22 & 0.47 \\
$D \bar{m}\left(F_{M} \rightarrow S\right)$ & -0.11 & 0.09 & 0.01 \\
$D \bar{m}\left(P_{M} \rightarrow S\right)$ & 0.49 & 0.04 & -0.04 \\
$D \bar{m}(M \rightarrow N)$ & 0.08 & -0.07 & 0.02 \\
Sum of outflows & 0.46 & 0.07 & -0.01 \\
Inflows and outflows & $\mathbf{1 . 7 2}$ & $\mathbf{- 0 . 1 5}$ & $\mathbf{0 . 4 6}$ \\
Other flows & 0.08 & 0.08 & 0.09 \\
Predicted change in $\bar{m}_{t}$ & 1.79 & -0.06 & 0.56 \\
Actual change in $m_{t}$ & 1.76 & -0.08 & 0.57 \\
\hline Women & $1976-1990$ & $1990-2000$ & $2000-2018$ \\
\hline$D \bar{m}\left(F_{S} \rightarrow M\right)$ & 1.23 & -0.16 & 0.78 \\
$D \bar{m}\left(P_{S} \rightarrow M\right)$ & 0.92 & 0.25 & 0.43 \\
$D \bar{m}(N \rightarrow M)$ & 0.25 & 0.12 & -0.02 \\
Sum of inflows & 2.40 & 0.20 & 1.20 \\
$D \bar{m}\left(F_{M} \rightarrow S\right)$ & 0.23 & 0.14 & -0.04 \\
$D \bar{m}\left(P_{M} \rightarrow S\right)$ & 1.09 & -0.01 & 0.01 \\
$D \bar{m}(M \rightarrow N)$ & 0.02 & 0.01 & 0.02 \\
Sum of outflows & 1.34 & 0.13 & -0.01 \\
Inflows and outflows & $\mathbf{3 . 7 4}$ & $\mathbf{0 . 3 4}$ & $\mathbf{1 . 1 9}$ \\
Other flows & -0.39 & 0.08 & -0.14 \\
Actual change in $m_{t}$ & 3.34 & 0.41 & 0.44 \\
\hline
\end{tabular}

Notes: LFS data, $1976 \mathrm{~m} 01-2018 \mathrm{~m} 12 . F_{S}$ : single jobholding with a full-time job; $P_{S}$ : single jobholding with a part-time job; $S=F_{S}+P_{S}$ : single jobholding; $F_{M}$ : multiple jobholding working fulltime on the main job; $P_{M}$ : multiple jobholding working part-time on the main job; $M=F_{M}+P_{M}$ : multiple jobholding; $N$ : nonemployment. For each worker flow (or group of worker flows) the table reports counterfactual change in the steady-state multiple jobholding share $\bar{m}_{t}$, and the change in the actual multiple jobholding share $m_{t}$ in the last row of each panel. All table entries are computed as the difference between the average level of the time series over the last year and first year of each subperiod. All table entries are in percentage points. 
inflows. During this subperiod, the inflows predict a $1.20 \mathrm{pp}$. increase to be compared with the 1.05 pp. predicted change of the multiple jobholding share. Overall, Table 4 delivers a clear message, that the increase of single jobholders' likelihood to take on a second job is the main driver of men's and women's multiple jobholding share.

Our framework distinguishes between full-time and part-time work when individuals hold either one or several jobs. This helps us refine the picture just described. As can be seen in Table 4, among men the dynamics of the inflows is overwhelmingly explained by the behavior of full-time workers $\left(F_{S}\right)$. Among women, changes within each subperiod are more balanced between those occurring among part-time and full-time workers. For instance, during the last subperiod the increase in full-time female workers' probability to take on a second job predicts an increase by $0.78 \mathrm{pp}$. The corresponding figure among part-timers is 0.43 . These observations illustrate, again, the usefulness of having this rich measurement framework. On a similar note, a strength of our statistical decomposition is that it detects changes that are partly masked by the 'stock-flow fallacy' illustrated in Table 4. That is, in several subperiods, the changes in stocks are actually lower than the changes implied by the gross flows taken in isolation. The decomposition quantifies those differences.

\subsection{A closer look at recession periods}

Before closing this section, we analyze the dynamics of multiple jobholding at higher frequencies, during the three recession episodes covered by our data. Our goal is to assess whether the longrun driving forces that we have detected - single jobholders' likelihood to take on second jobs - are also at work during recessions to explain the behavior of multiple jobholding shares. To address this question, we construct another set of counterfactual time series of evolution of the multiple jobholding share driven by contemporaneous and lagged changes in each flow hazard. This type of counterfactual, which is used by Elsby et al. [2015] to implement a dynamic variance decomposition of the U.S. unemployment rate, is well suited to capture short-run cyclical variations. We refer the reader to Elsby et al. [2015]'s paper for a presentation and detailed explanations of the workings of this type of counterfactual time series.

For each recession, the solid lines in Figure 5 denote changes (in percentage points) of 
Early-1980s recession
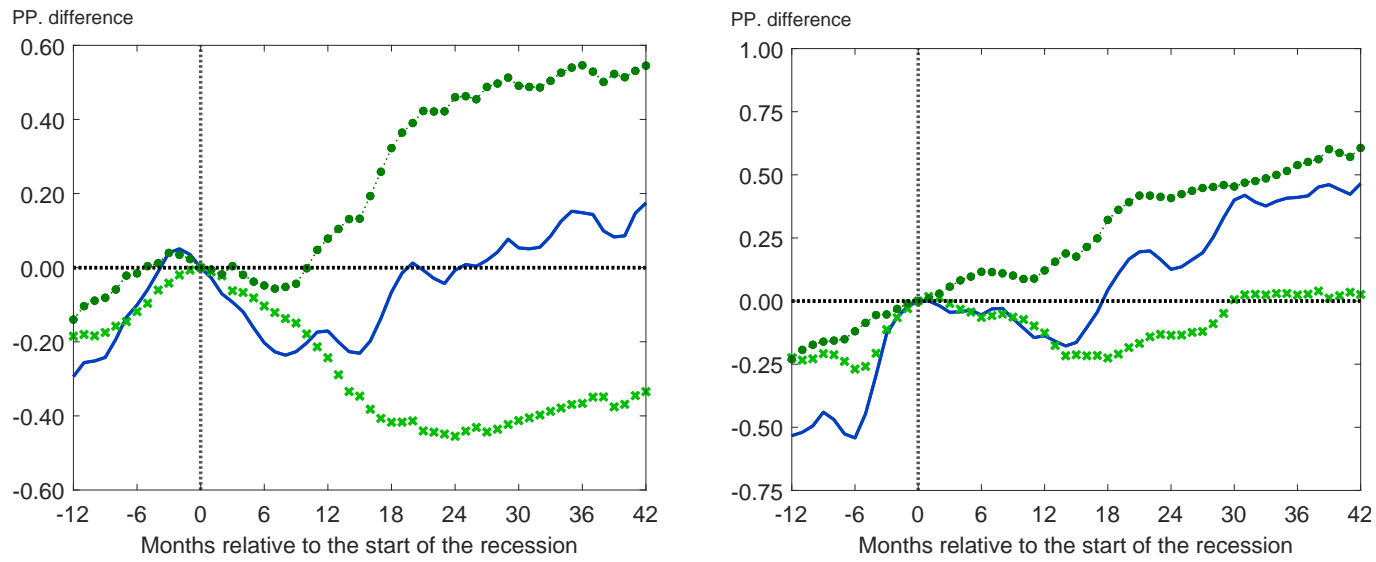

Early-1990s recession
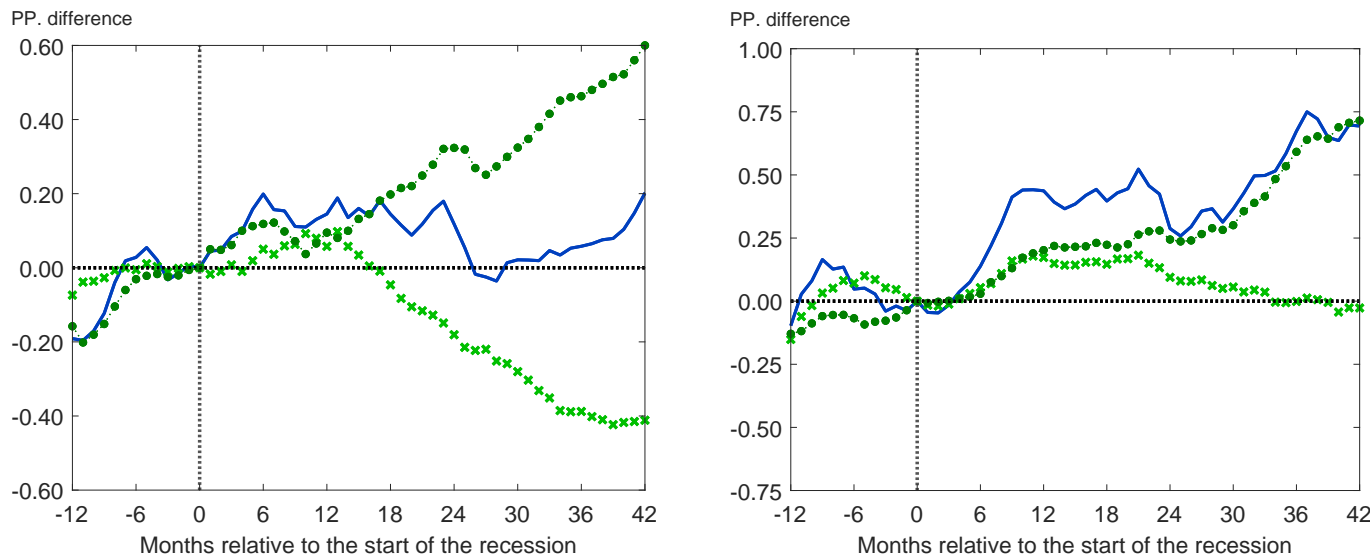

Recession of 2008-09
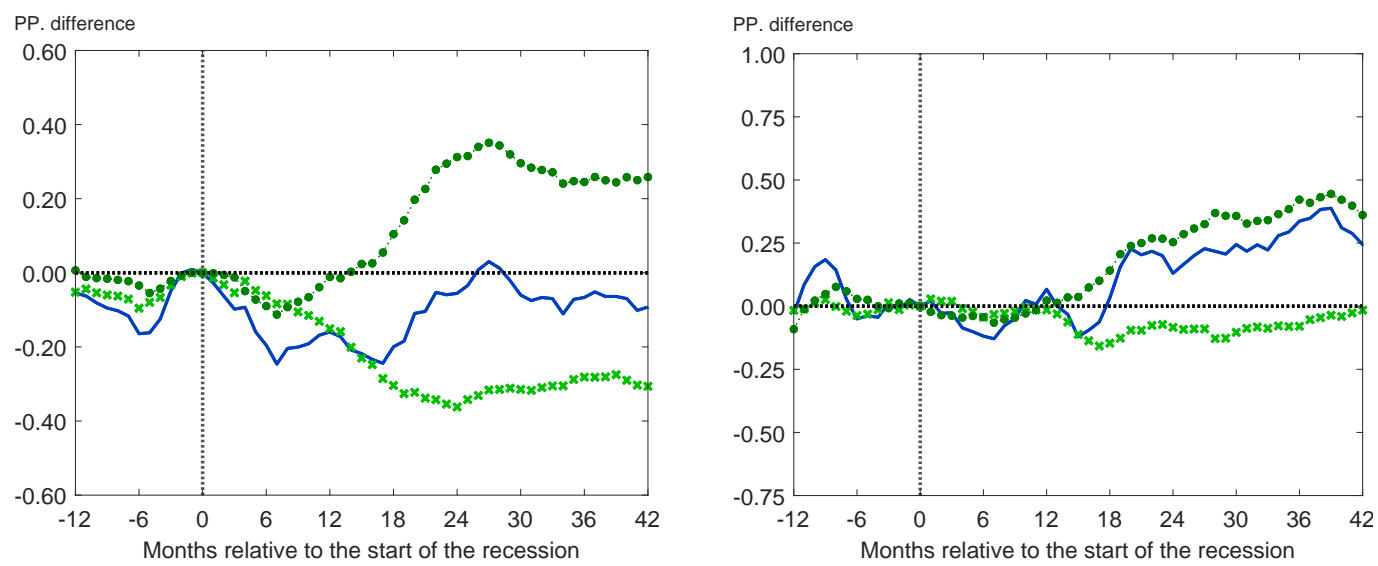

(a) Men

(b) Women

$$
\text { - Actual } \quad * \mathrm{~F}_{\mathrm{S}}+\mathrm{P}_{\mathrm{S}} \rightarrow \mathrm{M} \quad \bullet \mathrm{F}_{\mathrm{M}}+\mathrm{P}_{\mathrm{M}} \rightarrow \mathrm{S}
$$

Figure 5: Dynamics of multiple jobholding during recessions

Notes: LFS data. Solid lines: change in the multiple jobholding share from its value at time 0 , the starting month of the corresponding recession. Crossed (resp. dotted) lines: counterfactual changes driven by multiple jobholding inflows $F_{S}+P_{S} \rightarrow M$ (resp. multiple jobholding outflows $F_{M}+P_{M} \rightarrow S$ ). All time series are expressed in percentage points difference. 
the actual multiple jobholding share relative to its value at the beginning of the recession. The crossed and dotted lines show the counterfactual changes driven by the dynamics of the inflows and outflows, respectively. First, as can be eyeballed from the plots, the sum of the crossed and dotted lines tracks the solid line very closely in each recession. In other words, the counterfactual time series displayed in Figure 5 predict almost all the variations of recessionary changes in the multiple jobholding share. Second, there is a clear gender difference, in that the cyclical variations are lower for women than for men. This is consistent with the results we have obtained so far. Third, during recessions, we see a drop in both multiple jobholding inflows and outflows, which acts in opposite ways on the multiple jobholding share. Men's multiple jobholding share during the early-1980s recessions provides a clear illustration, where the share does not vary much because it is pulled in opposite directions by the inflows and outflows. Related, Figure 5 shows that the contribution of the outflows to the dynamics of multiple jobholding is comparable (in absolute terms) to the contribution of the inflows. Thus, while single jobholders' likelihood to take on a second job is the key driving force of multiple jobholding shares in the long run, its relative contribution is lower in the short run.

Interestingly, the empirical literature so far had failed to identify strong cyclical patterns in U.S. multiple jobholding time series (Amuedo-Dorantes and Kimmel [2009], Lalé [2016], Hirsch et al. [2016]). One might have hypothesized that this was due to the weak cyclicality of the factors that push individuals toward and away from working multiple jobs. Instead, the evidence presented in Figure 5 suggests that, at least for men, these factors are cyclical, but also that they are of similar magnitude and balance the effects of each other out. It is also worth noting that the cyclicality is more pronounced during the early 1980s and 1990s recessions than during the two recent decades. Due to data limitations, the empirical literature for the U.S. only looks at the last 20 to 25 years.

\section{Workers' reasons for holding multiple jobs}

We documented long-run increases in the shares of multiple jobholders among employed men and women in Canada. These are no measurement artifacts: the trends are not accounted for 
by compositional changes or time-aggregation bias. We devised a statistical decomposition to disentangle the role of several sources of changes in multiple jobholding. This exercise showed that the main driving force is the prolonged increase in the probability that single jobholders pick up second jobs. In this section, we use the wealth of auxiliary information available in the SWA and CSCE to shed light on the factors that might have contributed to this dynamics.

Flexibility of the work schedule. A central tenet of the analysis of multiple jobholding is that so-called 'hours constraints' on the main job might prompt workers to take on second jobs in order to increase their earnings. An oft-cited piece of evidence to support this hypothesis is that many workers report that they would work more hours if they could. ${ }^{18}$ The first point we wish to make is that 'hours constraints', which is somewhat of a catchall term, blends together two different stories about multiple jobholding. In the first one, the worker would have the opportunity to work more hours, but some aspects of the job prevents her from putting these hours to work on the main job. One reason could be that the worker is not paid by the hours in her main job, making it not worth the effort. ${ }^{19}$ Another reason could be that there is no demand for additional hours worked on the main job. The other story is that the constraints related to the schedule of the main job make it prohibitively costly to hold a second job, so that the worker does not have the opportunity to put more hours on another job. The next paragraph will shed light on these two versions of workers' 'hours constraints'.

Let us start with the evidence that workers might want to work more hours. Kahn and Lang [1995] report that, in the 1986 Survey of Work Reduction supplement of the LFS, 34.2 percent of workers would like to increase their hours and 17.3 percent would instead prefer to work fewer hours. In the 1995 wave of the SWA, we find that these numbers are respectively at 27.7 and 6.0 percent. That is already a substantial increase in the fraction of workers who are satisfied with their work schedule. Comparisons with figures from the 2019-2020 CSCE are

\footnotetext{
${ }^{18}$ In an insightful discussion of survey data on workers' stated reasons for holding several jobs, Kahn and Lang [2001] explain that, both in Canada and the U.S., most workers who are dissatisfied with their hours would like to work more, not fewer hours. In Europe, the data seem to suggest that the proportion of dissatisfied workers who would prefer to reduce their hours is significantly higher.

${ }^{19}$ Workers who are not paid by the hour make up for about 40 percent of employment in Canada. Data on hourly-paid employment, which come from the Survey of Employment, Payrolls and Hours, are only available starting in 2001. These data show a mild increase of hourly-paid employment from 59 percent in 2001 to 62 percent in 2018 (see Kostyshyna and Lalé [2019]).
} 


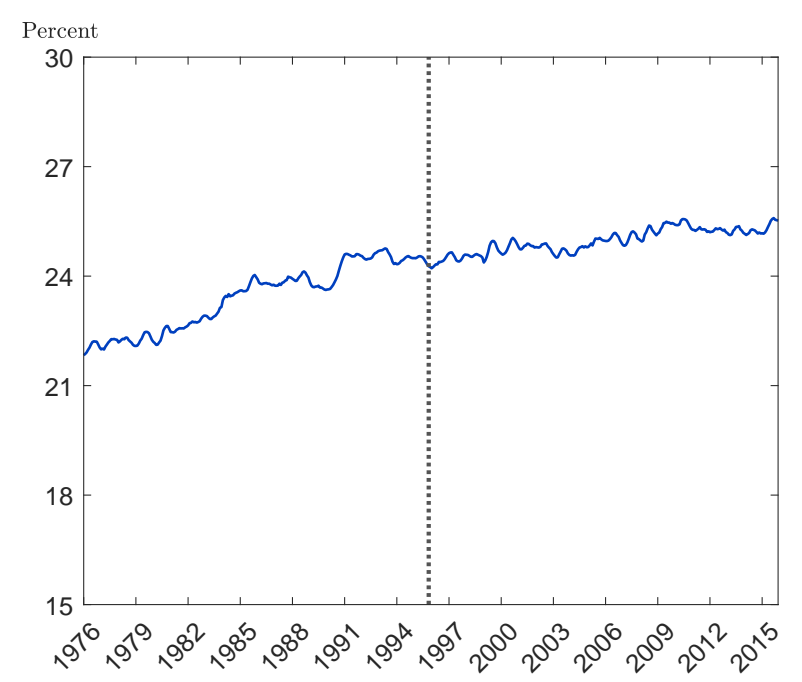

(a) Men

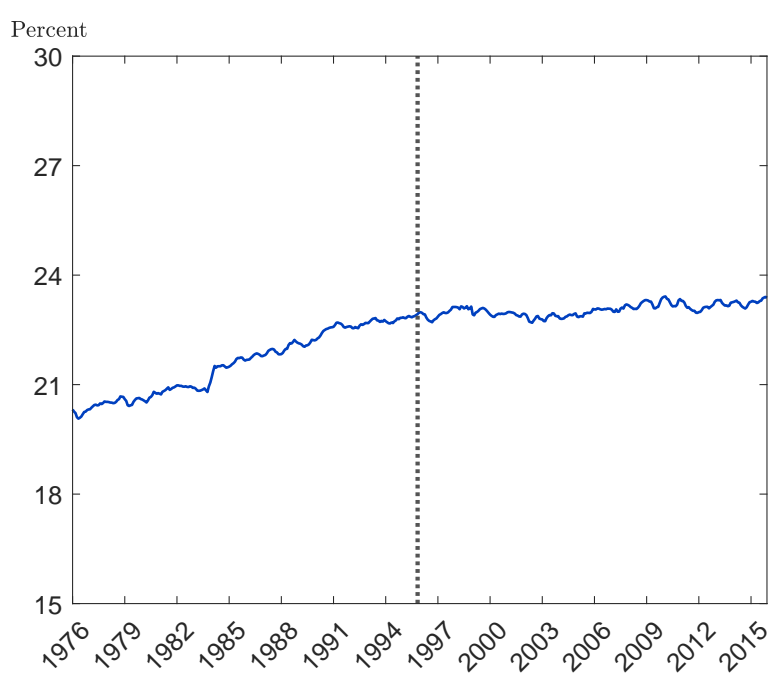

(b) Women

Figure 6: Flexibility of the work schedule (extrapolated using occupation data): 1976-2015

Notes: SWA data 1995 and LFS data 1976m01 - 2015m12. Index measuring the flexibility of individuals' work schedule. In November 1995 (marked by the vertical lines), the index shows the fraction of workers who can choose when the work day begins or ends. At other dates, it shows whether the employment structure shifts towards (increases relative to Nov. 1995) or away (decreases relative to Nov. 1995) occupations with a flexible work schedule. All time series are seasonally adjusted and smoothed by two-months, two-sided MA averaging.

harder to make because the CSCE question about desired work is too unspecific and might bias respondents towards reporting that they want fewer hours. ${ }^{20}$ With this caveat in mind, the fraction of workers who would like to work more hours in the 2019-2020 CSCE is down to 18.7 percent and the fraction who would prefer to work fewer hours is at 41.0 percent. Altogether, these numbers show, firstly, that there are fewer workers who want to work more hours and, second, that this is due to the fact that workers are more satisfied with their work schedule. The fraction of individuals who are satisfied with their work schedule increases slightly more among multiple jobholders, but the increase is too small to conclude that the trends are attributable to workers who manage to work enough hours by holding a second job.

Next, we investigate the role of the work schedule of workers' main job. We use respondents' answers to this question from the 1995 wave of the SWA: "In your (main) job, can you choose,

\footnotetext{
${ }^{20}$ Question wording is of first-order importance in this context: If the question does not spell out clearly that a change in hours would be accompanied by a proportional change in earnings, respondents tend to report lower desired hours (Kahn and Lang [2001]). For those who want to work more hours, on other hand, it seems clearer that the change in hours would be matched by a change in their earnings. In the SWA, the question is: "If you had the choice to increase/decrease the number of hours worked given your current wage rate, how many hours per week would you like to work?". In the CSCE on the other hand, the question is less clear: "How many hours would you have liked to work last week?".
} 
at least to some extent, when the work day begins or ends?". ${ }^{21}$ We interpret a positive answer as a proxy for a flexible work schedule. We tabulate the fraction of workers within each occupation $o$ who report having this flexibility, and denote it as flex ${ }_{o}{ }^{22}$ Letting $e_{o, t}$ denote the fraction of workers who are employed in occupation $o$ at time $t$ (computed from the LFS), we construct the following index: $\sum_{o} e_{o, t} \times$ flex $_{o}$. At the time of the SWA interview, the index gives the fraction of workers who can choose when the work day begins or ends. At other dates, under the (strong) assumption that flex $_{o}$ measures a permanent characteristic of occupations, the index shows if employment is shifting towards, or away from, occupations with a flexible work schedule. Figure 6 plots the index for male and female workers. The vertical line, which indicates the date of the SWA, shows that between 22 and 24 percent of workers can choose when the work day begins or ends. Over time, we see that both male and female employment moves towards occupations that provide workers with more flexibility. ${ }^{23}$ Not only is this consistent with the evidence that hours dissatisfaction has decreased over time, but it also suggests that the probability to move into multiple jobholding has increased because workers have more opportunity to put additional hours of work on a second job.

Main stated reasons for multiple jobholding. We now turn to multiple jobholders' stated reasons for holding a second job. The 1991 and 1995 waves of the SWA and the 2019-2020 panels of the CSCE ask respondents to choose one from the following list: 'meet regular household expenses', 'pay off debts', 'buy something special', 'save for the future', 'gain experience / build a business', 'enjoy the work from the second job', or 'other reasons'. As is common in the literature, we will refer to the first four items as "economic reasons for holding a second job" (though admittedly a misnomer, acquiring human capital and non-pecuniary returns to work can also be viewed as economic motives). Table 5 shows men's and women's stated reasons for

\footnotetext{
${ }^{21}$ Respondents are prompted to answer "Yes" or "No" to this question. Only 0.15 percent refuse to respond or choose "I don't know".

${ }^{22}$ We think that the work schedule is more directly tied an individual's occupation than to her industry of employment, and therefore focus on occupations. When we construct the index using industry codes, we find that it is flat for most of the sample period and that it increases towards the end of the sample.

${ }^{23}$ To be clear, the only source of variation over time in Figure 6 are changes in the occupational employment shares, $e_{o, t}$. Due to lack of data, we can measure fle $x_{o}$ at only one point in time. It might be that $f l e x_{o}$ decreases over time, which would attenuate or even revert the trends shown in Figure 6. But a more plausible dynamics is that flex $x_{o}$ increases over time too (see the last paragraph titled 'taking stock' in this section), so that our index is probably conservative.
} 
Table 5: Multiple jobholders' main reasons for holding a second job

\begin{tabular}{|l|ccc|ccc|}
\hline \hline & \multicolumn{3}{|c|}{ Men } & \multicolumn{3}{c|}{ Women } \\
\hline Meet regular household expenses & 1991 & 1995 & $2019-2020$ & 1991 & 1995 & $2019-2020$ \\
Pay off debts & 33.9 & 30.9 & 28.0 & 33.3 & 36.2 & 25.7 \\
Buy something special & 12.3 & 10.5 & 23.7 & 10.4 & 8.41 & 26.3 \\
Save for the future & 4.32 & 1.71 & 9.1 & 4.98 & 3.54 & 5.42 \\
Gain experience/build business & 14.5 & 12.2 & 14.0 & 12.4 & 9.17 & 19.7 \\
Enjoys the work from the second job & 9.54 & 17.3 & 11.0 & 12.1 & 13.4 & 9.40 \\
Other & 14.8 & 18.6 & 11.7 & 15.5 & 21.5 & 9.44 \\
\hline \hline
\end{tabular}

Notes: SWA data 1991 and 1995, and CSCE data 2019 and 2020. The table reports multiple jobholders' main reasons for holding a second job. All table entries are expressed in percent.

holding a second job according to the SWA and CSCE. While there are some male vs. female differences, in the next paragraphs we will focus on what is common across the two gender groups.

Table 5 shows that the main reasons for holding a second job in 1991 and 1995 are: 'meet regular household expenses' and 'save for the future'. The latter remains important in 20192020, while the motive 'pay off debts' grows in importance at the detriment of 'meet regular household expenses'. The quantitative differences might seem large, but one should bear in mind that the CSCE is more focused on issues related to household finances, which might have an impact on respondents' behavior. ${ }^{24}$ No matter the difference, the main point we wish to make is that adding up the first four items in Table 5 shows that economic reasons account for respectively 64.9 and 55.3 percent of men's multiple jobholding in 1991 and 1995, and 74.7 percent of their reasons for holding a second job in 2019-2020. For women, the numbers in 1991 and 1995 are respectively 61.0 and 57.4 percent vs. 77.1 percent in 2019-2020. A safe conclusion, given that we want to remain cautious when comparing results from the SWA and the CSCE, is that economic reasons for holding a second job have not become less important over time.

These findings are potentially informative about the propensity of single jobholders to take on a second job. Recall that, by construction, main reasons for holding a second job are only measured among the sample of individuals who self-selected themselves into multiple jobholding.

\footnotetext{
${ }^{24}$ The sample and data collection methods of the SWA and CSCE are also different, reflecting the fact that the surveys differ in terms of their purposes. For these reasons, one cannot read too much into the numbers when making comparisons across the two surveys.
} 
Thus, the relative stability of "economic reasons for holding a second job" in Table 5 suggests the reasons why single jobholders take on a second job have not changed much over time. ${ }^{25}$ Rising labour market insecurity (Vosko [2006]) and stagnant wages (Brouillette et al. [2017]) would seem to question this notion, but note that there are also remarkable patterns of stability in terms of job tenure distribution and job retention rates (Heisz [2005]) in Canadian data. In any case, examining how these patterns affect single jobholders' motives for taking on a second job is beyond the scope of our analysis. The key point is that the increase in the probability to take on a second job does not seem to be driven by a shift in the underlying motives of multiple jobholding.

Taking stock. Multiple jobholding, measured by the fraction of employed workers who hold more than one job, has become more common mainly because the probability that a single jobholder takes on a second job has increased over time. This probability is a function of the net present value of taking on a second job, and of the costs of doing so. We find evidence suggesting that workers enjoy a more flexible work schedule on their main job, which supports the view that the cost of holding a second job has decreased over time. Workforce management technologies that make it easier to coordinate different work schedules, or the increasing availability of work from home, are indeed expected to reduce the impact of additional commute time, fatigue, set-up costs, etc. related to the second job. The direct cost of finding a second job is also likely to have decreased, due to online job search and the rise of the 'gig economy'. At the same time, some of, but not all, the evidence reported in this section is consistent with an increase in the net present value of taking on a second job. If workers enjoy a more flexible schedule on the first job, they might be able to extract a higher income from a second job. On the other hand, we see that workers are increasingly satisfied with the number of hours they work, which should lower the value of holding a second job to alleviate hours constraints on the main job. Last, despite a large increase in the number of workers who self-select themselves into multiple

\footnotetext{
${ }^{25}$ Of course, the outflow of multiple jobholding might also have an effect on the composition of multiple jobholders in terms of stated reasons for holding a second job. For example, suppose that many more workers are willing to take on a second job to gain experience (5th item listed in Table 5). Also, suppose that the process of gaining experience becomes much faster, meaning that multiple jobholders who report 'gain experience/building business' as their main motive leave the pool of multiple jobholding at a higher rate. In this scenario, the composition of multiple jobholders in terms of stated reasons might remained unchanged even though the motives for self-selection into multiple jobholding have shifted over time.
} 
jobholding, it seems that the underlying motives for doing so have remained stable. For the vast majority, economic reasons remain the main motive.

\section{Conclusion}

From mid-1970s until today, the share of multiple jobholders among employed workers has increased spectacularly in Canada. In this paper, we documented these changes, provided a comprehensive account of the role of the inflows and outflows in driving this dynamics, and offered suggestive evidence about some potential explanations. Our main conclusion is that the trend is chiefly explained by the increased likelihood of single jobholders to pick up second jobs. Doing so has become less costly because workers seem to enjoy a more flexible work schedule on their main job.

An important endeavor for future research is to distinguish better between the costs and benefits of multiple jobholding. We only get a first grip on this issue by using data on workers' stated reasons for holding a second job. Quantitative job search models of multiple jobholding, such as those developed by Lalé [2019] and Mancino and Mullins [2020], could be very helpful for making further investigations in this direction. The data moments of our analysis (averages of worker flows, comovements between transition probabilities and the business cycle, etc.) would be informative to calibrate this type of models. Further, these models could be used to study whether the trends in multiple jobholding can be related to changes in Canada's labour market policies. As pointed out by Kimmel and Powell [1999], the demand and supply sides of multiple jobholding might have been affected by changes in payroll taxes on work above a certain hour, changes in real minimum wages, and adjustments in parental leave policies. These are all questions worth pursuing in future research.

\section{References}

Katharine Abraham, John C Haltiwanger, Kristin Sandusky, and James R Spletzer. Measuring the gig economy: Current knowledge and open issues. In Carol A Corrado, Jonathan Haskel, 
Javier Miranda, and Daniel E Sichel, editors, Measuring and Accounting for Innovation in the 21st Century. University of Chicago Press (forthcoming), March 2017.

George A Akerlof and Brian G M Main. Pitfalls in Markov modeling of labor market stocks and flows. Journal of Human Resources, 16(1):141-151, 1981.

Catalina Amuedo-Dorantes and Jean Kimmel. Moonlighting over the business cycle. Economic Inquiry, 47(4):754-765, 2009.

Olivier Blanchard and Peter Diamond. The cyclical behavior of the gross flows of US workers. Brookings Papers on Economic Activity, 21(2):85-156, 1990.

Olivier Blanchard and Pedro Portugal. What hides behind an unemployment rate: Comparing Portuguese and US labor markets. American Economic Review, 91(1):187-207, 2001.

Daniel Borowczyk-Martins and Etienne Lalé. Employment adjustment and part-time work: Lessons from the United States and the United Kingdom. American Economic Journal: Macroeconomics, 11(1):389-435, January 2019.

Daniel Borowczyk-Martins and Etienne Lalé. The ins and outs of involuntary part-time employment. Labour Economics, (forthcoming), December 2020.

Dany Brouillette, James Ketcheson, Olena Kostyshyna, and Jonathan Lachaine. Wage growth in Canada and the United States: Factors behind recent weakness. Bank of Canada Staff Analytical Note 2017-8, 2017.

Patricia Cohen. In picking up work here and there, many miss out on unemployment check. The New York Times, July 2020. https://nyti.ms/3fZFDyY (accessed December 1, 2020).

Karen Smith Conway and Jean Kimmel. Male labor supply estimates and the decision to moonlight. Labour Economics, 5(2):135-166, 1998.

Karen Smith Conway and Jean Kimmel. Who moonlights and why? Evidence from the SIPP. Industrial Relations: A Journal of Economy and Society, 40(1):89-120, 2001. 
Michael Darby, John Haltiwanger, and Mark Plant. The ins and outs of unemployment: The ins win. NBER Working Paper 1997, 1986.

Paul Davidson. The job juggle is real. Many Americans are balancing two, even three gigs. USA Today, October 2016. https://www.usatoday.com/story/money/2016/10/ 17/job-juggle-real-many-americans-balancing-two-even-three-gigs/92072068/ (accessed December 1, 2020).

Michael WL Elsby, Bart Hobijn, and Ayşegül Şahin. On the importance of the participation margin for labor market fluctuations. Journal of Monetary Economics, 72:64-82, 2015.

Andrew Heisz. The evolution of job stability in Canada: Trends and comparisons with US results. Canadian Journal of Economics, 38(1):105-127, 2005.

Barry T Hirsch and John V Winters. Rotation group bias in measures of multiple job holding. Economics Letters, 147:160-163, 2016.

Barry T Hirsch, Muhammad M Husain, and John V Winters. Multiple job holding, local labor markets, and the business cycle. IZA Journal of Labor Economics, 5(1):1-29, 2016.

Barry T Hirsch, Muhammad M Husain, and John V Winters. The puzzling pattern of multiple job holding across US labor markets. Southern Economic Journal, 84(1):26-51, 2017.

Jaroslava Hlouskova, Panagiotis Tsigaris, Anetta Caplanova, and Rudolf Sivak. A behavioral portfolio approach to multiple job holdings. Review of Economics of the Household, 15(2): 669-689, 2017.

Shulamit Kahn and Kevin Lang. Hours constraints: Theory, evidence and policy implications. In Ging Wong and Garnett Picot, editors, Working Time in Comparative Perspective (Volume 1). W.E. Upjohn Institute for Employment Research, 2001.

Shulamit B Kahn and Kevin Lang. The causes of hours constraints: Evidence from Canada. Canadian Journal of Economics, 28(4a):914-928, 1995.

Lawrence F Katz and Alan B Krueger. The rise and nature of alternative work arrangements in the United States, 1995-2015. Industrial \& Labor Relations Review, 72(2):382-416, 2019. 
Jean Kimmel and Lisa M Powell. Moonlighting trends and related policy issues in Canada and the United States. Canadian Public Policy, 25(2):207-231, 1999.

Olena Kostyshyna and Etienne Lalé. On the evolution of multiple jobholding in canada. Bank of Canada Working Paper 2019-49, 2019.

Pramila Krishnan. The economics of moonlighting: A double self-selection model. Review of Economics and Statistics, 72(2):361-67, 1990.

Etienne Lalé. The evolution of multiple jobholding in the U.S. labor market: The complete picture of gross worker flows. IZA Working Paper 10355, 2016.

Etienne Lalé. Search and multiple jobholding. Upjohn Institute Working paper 19-305, April 2019.

Antonella Mancino and Joseph L Mullins. Frictional adjustment to income tax incentives: An application to the Earned Income Tax Credit. Unpublished working paper, May 2020.

Stefanie Marotta. Working two jobs: How the side hustle is helping millennials get ahead in a challenging economy. The Globe and Mail, September 2020. https://www . theglobeandmail.com/investing/personal-finance/young-money/ article-working-two-jobs-how-the-side-hustle-is-helping-millennials-get-ahead (accessed December 1, 2020).

Georgios A Panos, Konstantinos Pouliakas, and Alexandros Zangelidis. Multiple job holding, skill diversification, and mobility. Industrial Relations: A Journal of Economy and Society, $53(2): 223-272,2014$.

Christina H Paxson and Nachum Sicherman. The dynamics of dual-job holding and job mobility. Journal of Labor Economics, 14(3):357-393, 1996.

James M. Poterba and Lawrence H Summers. Reporting errors and labor market dynamics. Econometrica, 54(6):1319-38, 1986.

Konstantinos Pouliakas. Multiple job-holding: Career pathway or dire straits? IZA World of Labor, May 2017. 
Andy Puzder. Does everyone have two jobs? A critical look at the left's latest economic talking point. Wall Street Journal (Online), July 2018. https://www.wsj.com/articles/ does-everyone-have-two-jobs-1532474015?reflink=desktopwebshare_permalink (accessed December 1, 2020).

Robert Shimer. Reassessing the ins and outs of unemployment. Review of Economic Dynamics, 15(2):127-148, 2012.

Robert Shishko and Bernard Rostker. The economics of multiple job holding. American Economic Review, 66(3):298-308, 1976.

Statistics Canada. Guide to the Labour Force Survey. August 2017. https: //www150. statcan . gc.ca/n1/pub/71-543-g/71-543-g2017001-eng.htm.

Jeannine Usalcas and Mark Kinack. History of the Canadian labour force survey, 1945 to 2016. Statistics Canada Technical Papers, January 2017. https://www150.statcan.gc.ca/n1/ pub/75-005-m/75-005-m2016001-eng.htm.

Leah F Vosko. Precarious employment: Understanding labour market insecurity in Canada. Montreal: McGill-Queen's University Press, 2006. 


\section{Appendices}

\section{A LFS data details}

To measure worker flows, we longitudinally match LFS respondents using household and personal identifiers. We check whether the longitudinal links are valid by applying a gender and age filter, meaning that we discard those links where gender changes or age increases by more than one year or decreases over consecutive months. Figure A1 shows the conditional matching rates resulting from this process; conditional matching rates are the shares of respondents from rotation groups 1 to 5 of the LFS who can be linked across two consecutive months. The sample average of the time series, shown by the dashed line, is equal to 94.2 percent. This number is very much in line with the matching rates that researchers obtain when working with data from the CPS. It also worth noting that conditional matching rates in the LFS have generally improved over time. The other salient patterns in Figure A1 are a somewhat prolonged reduction between 2000 and 2004 as well as sudden and short-lived drops of matching rates. In the next paragraph, we describe briefly the changes in the methodology of the LFS that seem to explain these patterns. Our account is based on Usalcas and Kinack [2017]'s history of the LFS.

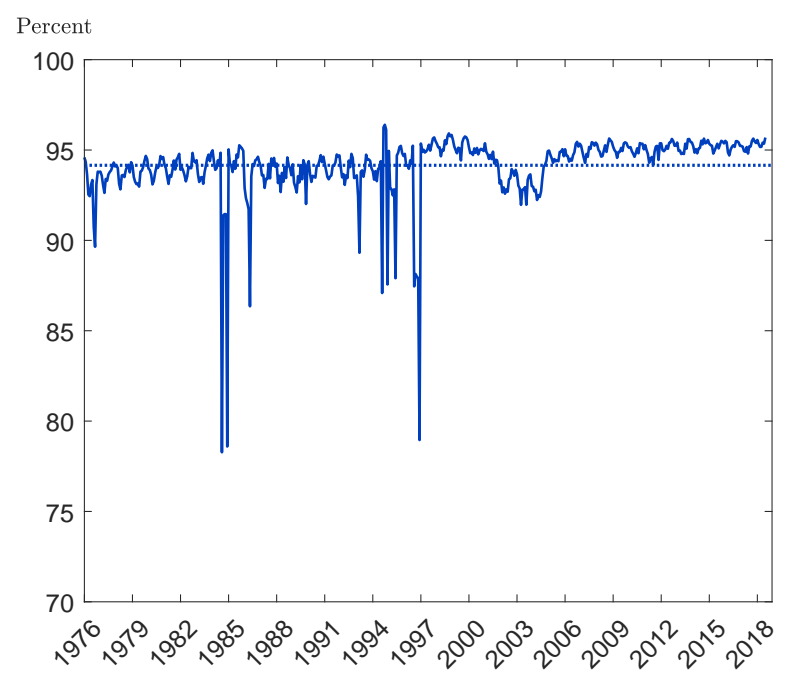

Figure A1: Conditional matching rates in the Labour Force Survey: 1976-2018

Notes: LFS data, $1976 \mathrm{~m} 01-2018 \mathrm{~m} 12$. Share (in percent) of respondents in rotation groups 1-5 of the LFS who can be linked across two consecutive months of the survey.

The LFS underwent a first set of important changes between 1984 and 1985: telephone interviewing was introduced for households in rotation groups 2-6 living in small urban and rural areas, and the sample was redesigned to obtain a better coverage of sub-provincial areas. The latter change was phased in from October 1984 to March 1985. In 1986, the sample size of the LFS was reduced by by randomly selecting and dropping households. A second set of major changes to the LFS took place in 1994 through 1997. In 1994, paper and pencil questionnaires were replaced by computer-assisted interviewing (CAI). Then, in 1996 and 1997, the questionnaire was deeply redesigned to fully exploit CAI, with a view to minimize response burden. In parallel, a redesigned sample (in 1995) and new method of compensating for household nonresponse were introduced. The third major change is the adoption of centralized CAI, meaning that these interviews are conducted from a centralized location within the regional offices. It 
was implemented during the Summer of 2000, which is when the matching rates in Figure A1 decrease to about 92-93 percent. Starting in November 2004 (which is when the matching rates recover), another redesign of the sample was introduced. The redesigned sample exploits improved information from the Census and the Address Register to better target subpopulations and reduce coverage in areas that are too difficult to survey.

The second (1994) and third (2000) waves of changes to the LFS generate discontinuities in the raw LFS data of gross worker flows. We remove these data discrepancies by using multiplicative adjustment factors. Specifically, for each time series of gross worker flows, we take the ratio of the mean value for the years just before and after the discontinuity, and multiply data before the date of the discontinuity by this ratio.

\section{B Correction procedures}

Our time series of stocks and gross worker flows are subjected to several adjustments. We first correct the raw data for two discontinuities created by methodological changes in the LFS (Appendix A). Then we filter out systematic seasonal variations using the U.S. Census Bureau's X-13ARIMA-SEATS program. Using the filtered time series, we divide the gross flow of workers from state $i$ to state $j$ during month $t$ by the stock of worker in state $i$ in month $t-1$ to obtain transition probability $p(i \rightarrow j)$. Then we adjust the set of transition probabilities to account for margin error and time aggregation.

Margin error. The goal of margin-error adjustments is to address the discrepancy between the stocks and gross worker flows data. The stocks are computed using cross-sectional data 'only'. On the other hand, the gross worker flows require longitudinal linking, and therefore their measurement suffers from sample attrition, imperfect matching, etc. The margin-error adjustment reconciles the changes in stocks predicted by the gross flows data with the actual changes calculated using cross-sectional data.

The starting point of margin-error adjustment is the Markov chain structure that underlies our analysis in Section 4. For convenience, we repeat equation (4) here:

$$
\ell_{t}=\boldsymbol{X}_{t} \ell_{t-1}
$$

In this equation, $\boldsymbol{\ell}_{t}$ is a vector of the stocks in each of the states of the Markov chain, and $\boldsymbol{X}_{t}$ is a stochastic matrix. We follow Elsby et al. [2015] and rewrite the dynamics of changes in stocks in the following way:

$$
\Delta \boldsymbol{\ell}_{t}=\boldsymbol{L}_{t-1} \boldsymbol{p}_{t}
$$

$\boldsymbol{p}_{t}$ is a column vector containing all month- $t p(i \rightarrow j)$ such that $i \neq j$, and $\boldsymbol{L}_{t-1}$ is a conformable matrix of stocks in the previous month. At this point we only have at hand unadjusted transition probabilities, which we denote as $\widehat{\boldsymbol{p}}_{t}$. In equation (B.2) on the other hand, $\boldsymbol{p}_{t}$ denotes the 'true', i.e. stock-consistent transition probabilities. We recover $\boldsymbol{p}_{t}$ by minimizing the weighted sum of squares of margin-error adjustments under the constraint of equation (B.2), i.e. we solve:

$$
\min \left(\boldsymbol{p}_{t}-\widehat{\boldsymbol{p}}_{t}\right)^{\prime} \boldsymbol{W}_{t}^{-1}\left(\boldsymbol{p}_{t}-\widehat{\boldsymbol{p}}_{t}\right) \text { s.t. } \Delta \boldsymbol{\ell}_{t}=\boldsymbol{L}_{t-1} \boldsymbol{p}_{t}
$$

In this minimization problem, $\boldsymbol{W}_{t}$ is a weighing matrix proportional to the covariance matrix of $\widehat{\boldsymbol{p}}_{t}$ (see Elsby et al. [2015] and Borowczyk-Martins and Lalé [2020]). The solution of this minimization problem, $\boldsymbol{p}_{t}$, is a function of $\widehat{\boldsymbol{p}}_{t}, \boldsymbol{L}_{t-1}, \Delta \boldsymbol{\ell}_{t}$, which we have already computed. 
Time-aggregation bias. The idea behind the adjustment for time-aggregation bias is explained in Section 4. Our adjustment procedure is based on the continuous-time correction developed by Shimer [2012]. We describe it here briefly for completeness.

To maintain consistency with the notations of the main text, denote by $\boldsymbol{H}_{t}$ the continuoustime analog of $\boldsymbol{X}_{t}$. It is known that if the eigenvalues of $\boldsymbol{H}_{t}$ are all distinct, then $\boldsymbol{H}_{t}$ can be written as: $\boldsymbol{H}_{t}=\boldsymbol{V}_{t} \boldsymbol{C}_{t} \boldsymbol{V}_{t}^{-1}$, where $\boldsymbol{C}_{t}$ is a diagonal matrix of eigenvalues and $\boldsymbol{V}_{t}$ is the matrix of associated eigenvectors. Furthermore, one can show that $\boldsymbol{X}_{t}$ can be decomposed as: $\boldsymbol{X}_{t}=\boldsymbol{V}_{t} \boldsymbol{D}_{t} \boldsymbol{V}_{t}^{-1}$, where $\boldsymbol{D}_{t}$ is a diagonal matrix whose elements are the exponentiated eigenvalues in $\boldsymbol{C}_{t}$, and that this relationship is unique if the eigenvalues of $\boldsymbol{D}_{t}$ are, in addition to distinct, real and nonnegative. These relationships can be used to obtain time series of estimates of the adjusted hazard rates $\lambda_{t}^{i j}$. So, in every month $t$, we compute the eigenvalues of the discrete transition matrix $\boldsymbol{X}_{t}$ and check whether they are all distinct, real and nonnegative. We then take their natural logarithm to obtain the eigenvalues of the continuous-time analogue $\boldsymbol{H}_{t}$. Finally, we compute $\lambda_{t}^{i j}$, and use the relationship: $p_{t}(i \rightarrow j)=1-e^{-\lambda_{t}^{i j}}$ to obtain a series of time-aggregation adjusted transition probabilities.

\section{Compositional changes}

We look at the effects of compositional changes to investigate further the role played by heterogeneity in the dynamics of the multiple jobholding share (Subsection 3.3). Specifically, for both gender groups, we construct counterfactual multiple jobholding shares that control (in isolation) for changes in the composition of employment with respect to age (5 subgroups), education (4 subgroups), marital status (3 subgroups) or industry (12 subgroups). The age, education, marital status and industry subgroups are those listed in Table 2 in the main text. Letting $g$ denote the subgroups of a given category, the multiple jobholding share is

$$
m_{t}=\sum_{g} \omega_{g, t} m_{g, t}
$$

where $\omega_{g, t}$ is the employment share of subgroup $g$ at time $t$, and $m_{g, t}$ is subgroup $g$ 's own multiple jobholding share. To calculate counterfactual $m_{t}$ 's, we hold the $\omega_{g, t}$ 's constant over time (we fix them to their sample mean).

The plots in Figure C1 compare the actual multiple jobholding share (denoted by the dashed line) with the counterfactual time series (denoted by the solid lines) for men (Plot $\mathrm{C} 1 \mathrm{a})$ and women (Plot C1b). For men, it is hard to discern any difference between the roles of age, education, marital status and primary industry of employment. Starting in the mid1990s, changes in men's employment share across these categories contributed to raising the multiple jobholding share - the measured share $m_{t}$ is higher than the counterfactual $m_{t}$. For instance, men's employment shifts towards older and more educated men, who also experience larger increases of their own $m_{g, t}$ during this period (see Table 2). Quantitatively, the largest effect comes from education: without the shift towards more educated workers, men's multiple jobholding share would have been lower by 0.75 percentage points in 2018 . For women, the roles played by age, education, marital status and industry are somewhat different from each other. For instance, controlling for changes in age lowers the multiple jobholding share at the beginning of the sample period, while changes in education and industry, once controlled for, lower the multiple jobholding share at the end of the period. No matter the differences, Figure C1 shows that, in quantitative terms, compositional changes play a minor role in men's and virtually no role in women's multiple jobholding share. 

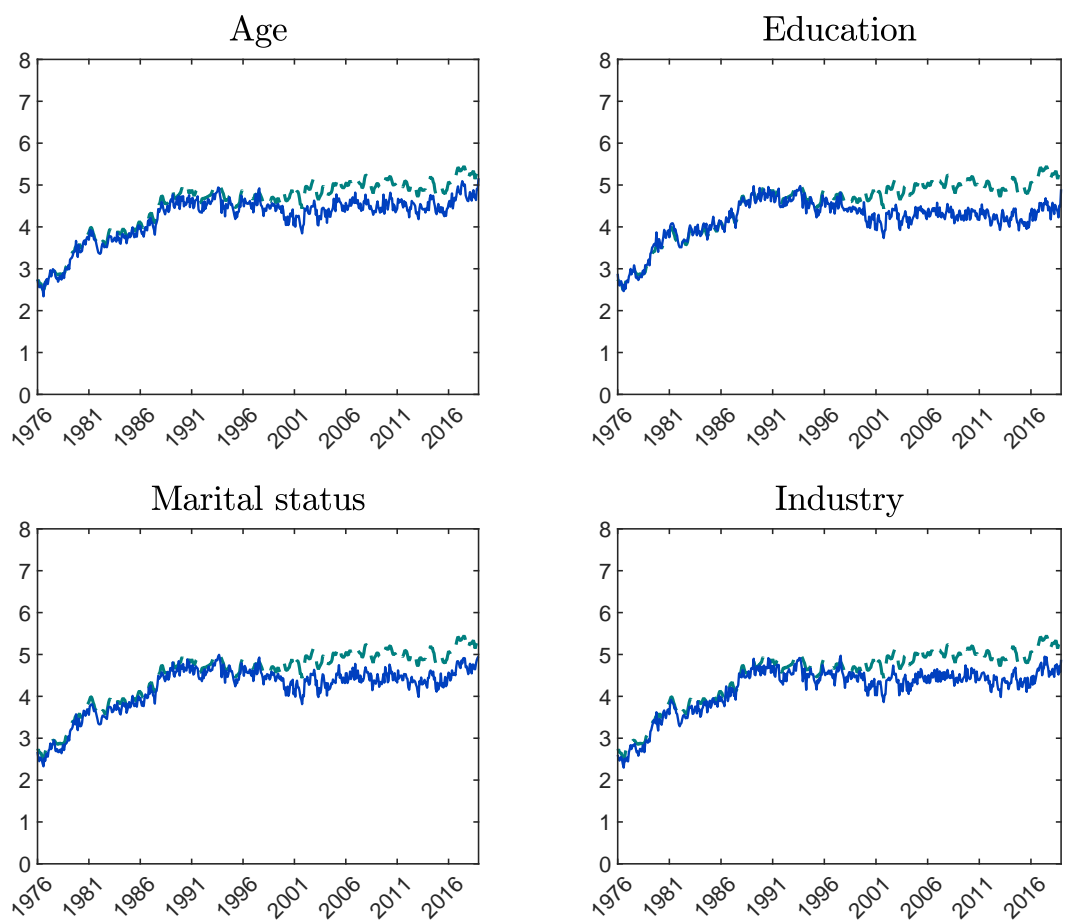

(a) Men
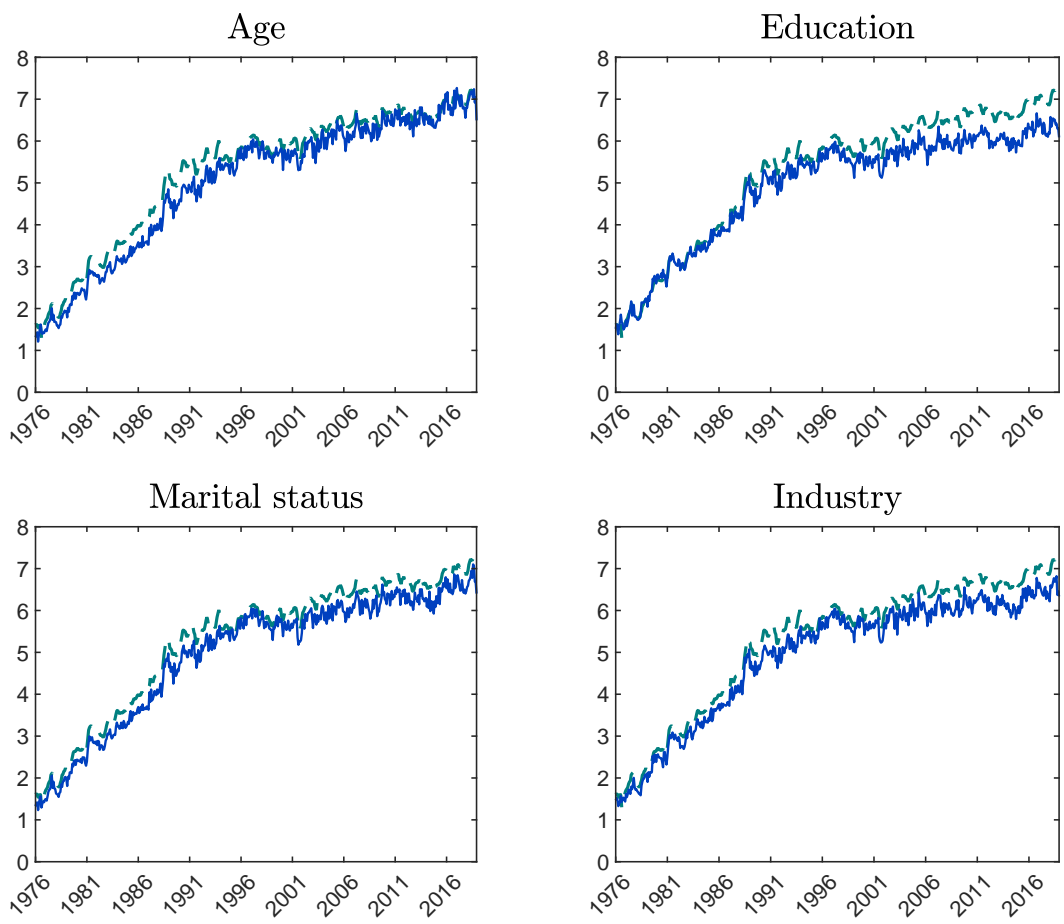

(b) Women

\section{- - -Baseline —Adjusted for compositional changes}

Figure C1: Multiple jobholding, controlling for compositional changes: 1976-2018

Notes: LFS data, 1976m01 - 2018m12. Multiple jobholders as a share (in percent) of all employed individuals. Dashed lines: baseline multiple jobholding share plotted in Figure 2. Solid line: counterfactual multiple jobholding shares that control for changes in the composition of employment. All time series are seasonally adjusted. 
Supplementary material

[Not intended for publication] 

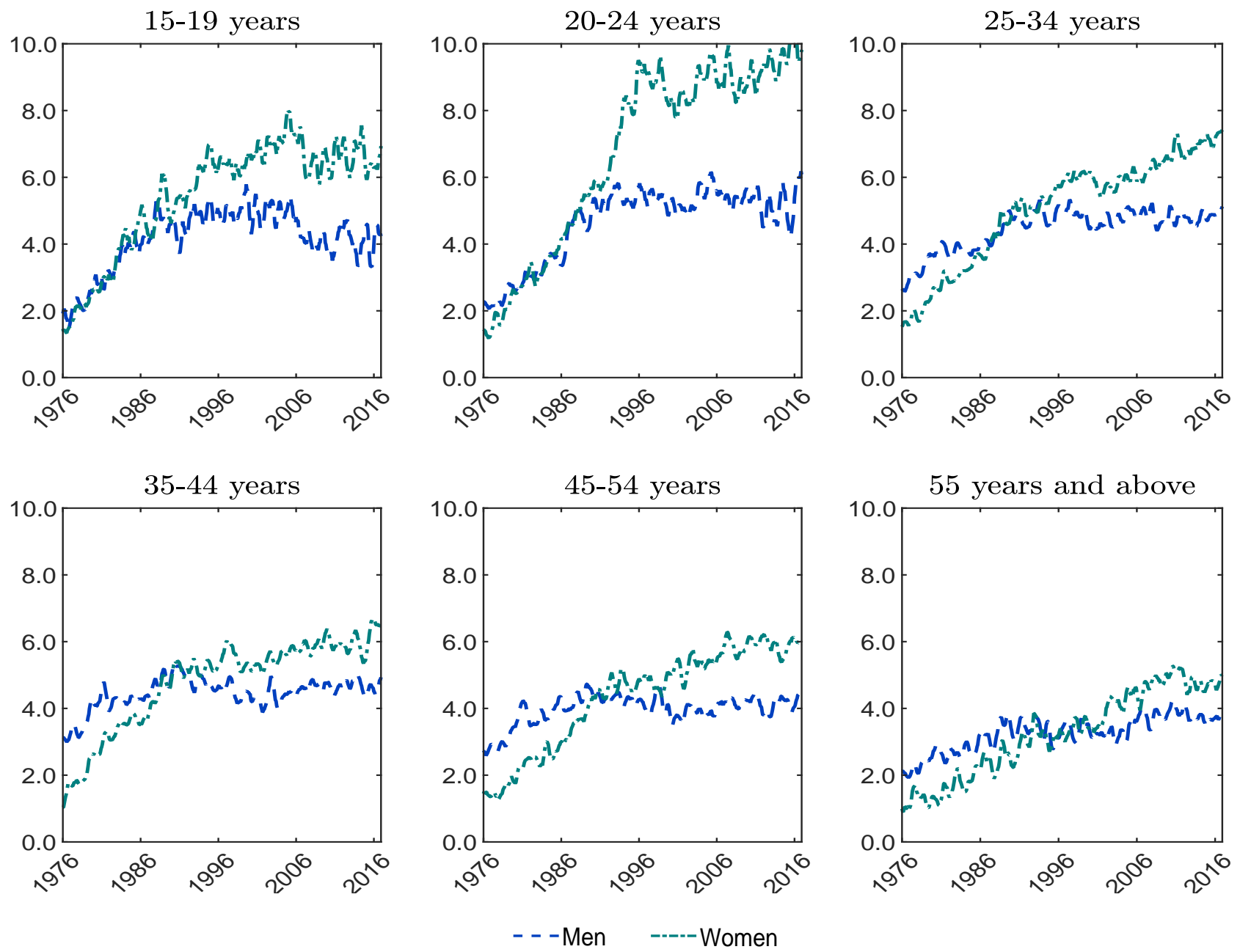

Figure S1: The multiple jobholding share, by age: 1976-2018

Notes: LFS data, 1976m01 - 2018m12. Multiple jobholders as a share (in percent) of all employed individuals (within each age group, for men and women). All time series are seasonally adjusted and smoothed by three-months, two-sided MA averaging. 

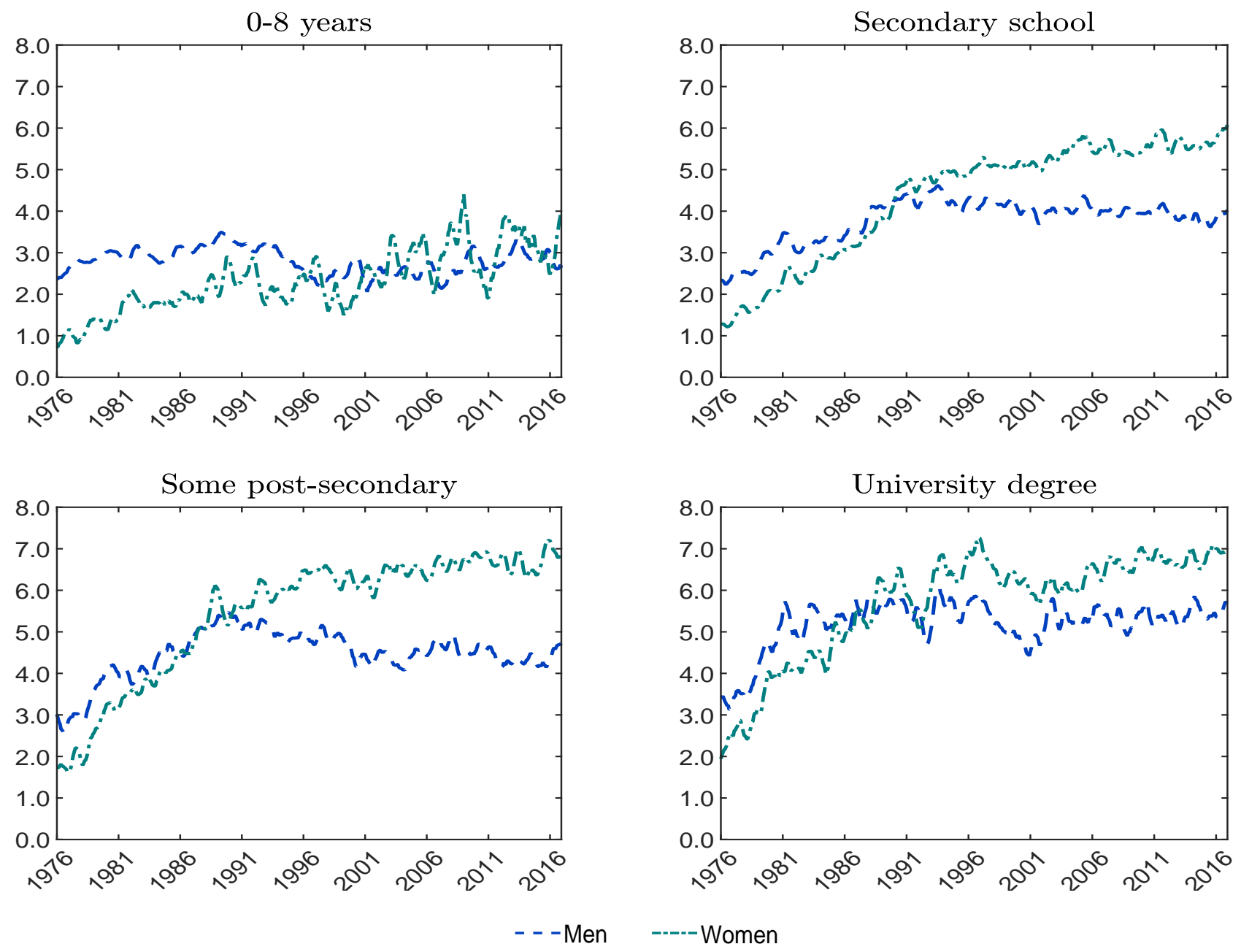

Figure S2: The multiple jobholding share, by education: 1976-2018

Notes: LFS data, 1976m01 - 2018m12. Multiple jobholders as a share (in percent) of all employed individuals (within each education group, for men and women). All time series are seasonally adjusted and smoothed by three-months, two-sided MA averaging. 

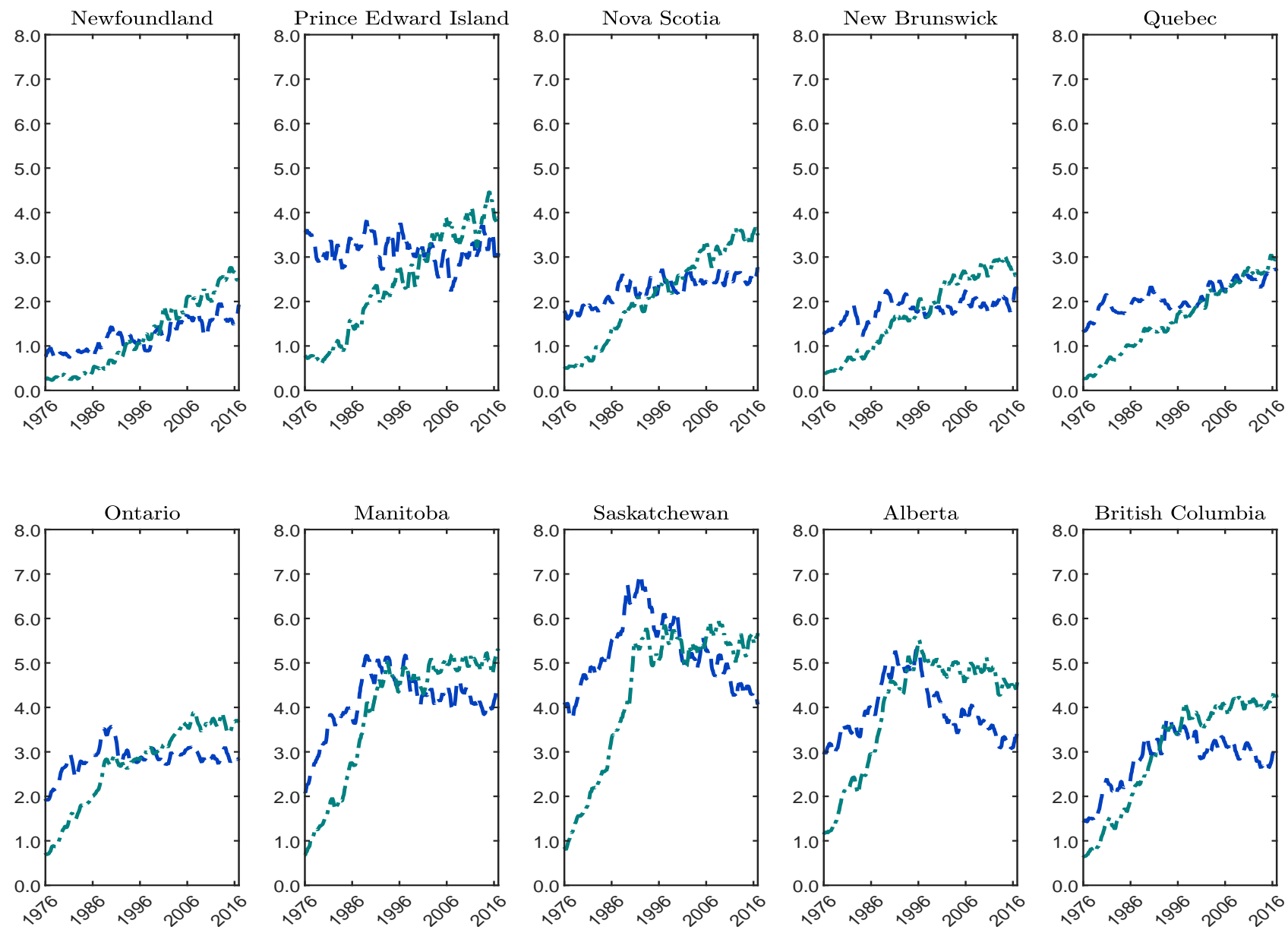

- - -Men -----Women

Figure S3: The multiple jobholding share, by provinces: 1976-2018

Notes: LFS data, 1976m01 - 2018m12. Multiple jobholders as a share (in percent) of all employed individuals (within each province, for men and women). All time series are seasonally adjusted and smoothed by three-months, two-sided MA averaging. 

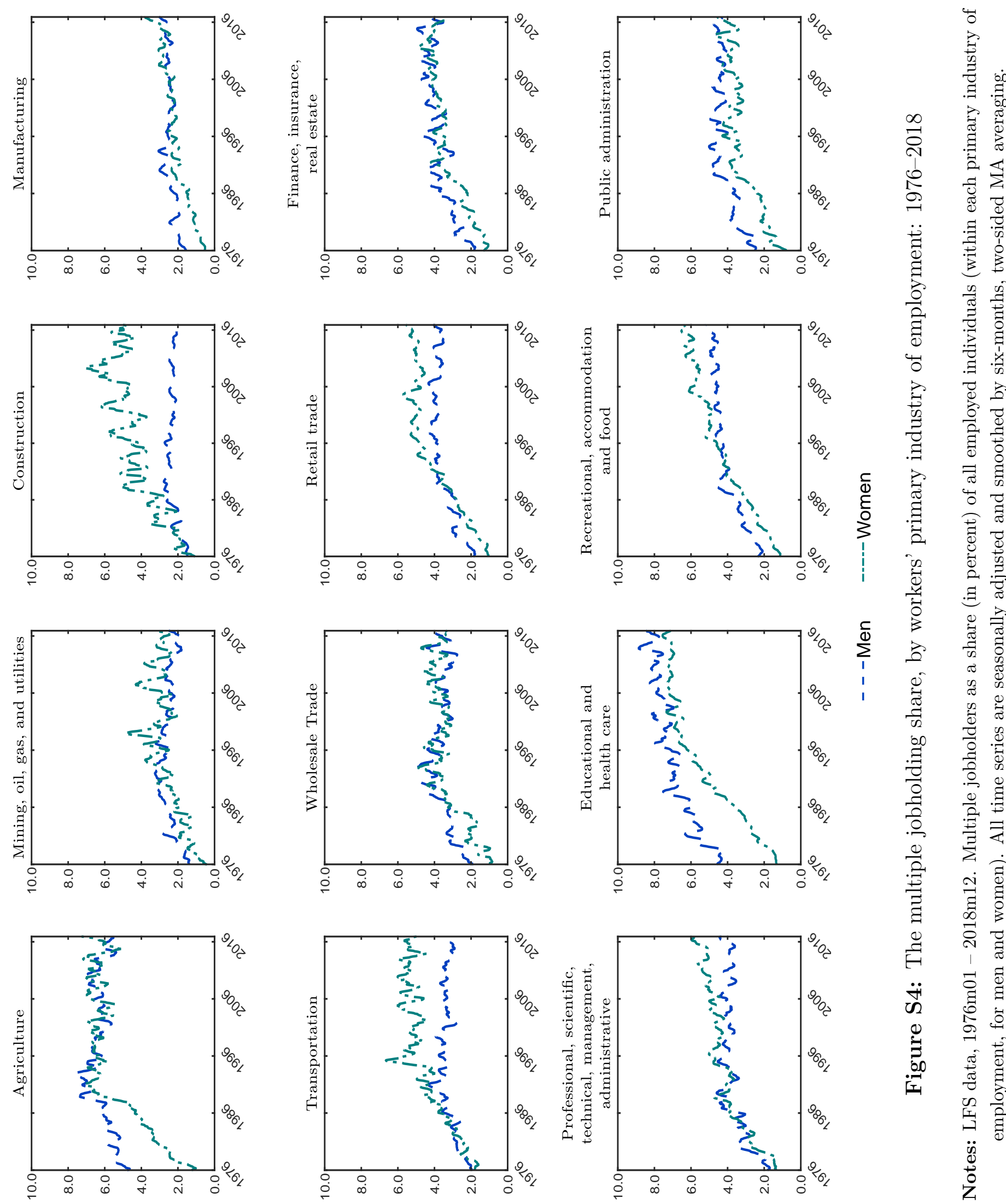

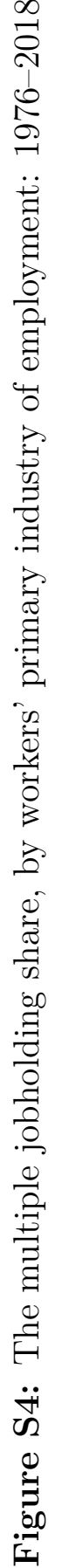

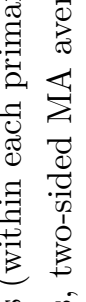

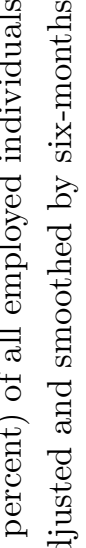
丰

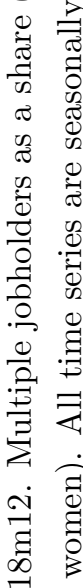
究 है छี 过 敢 帝 贡 茴 $\ddot{g}$
$\dot{0}$
$Z$ 

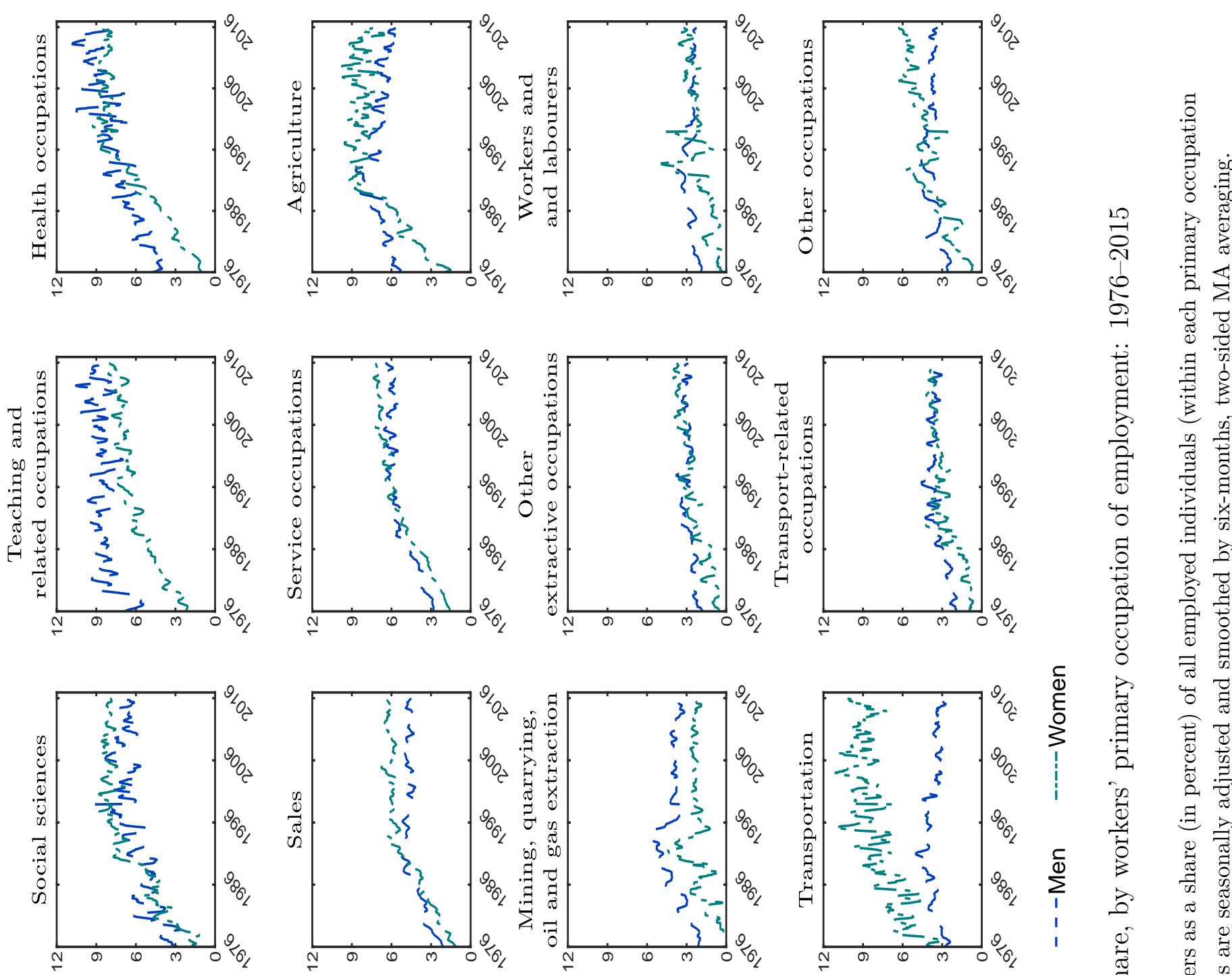

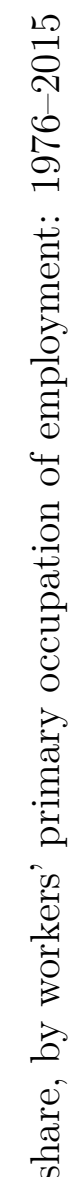

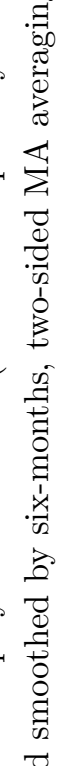

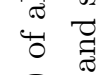
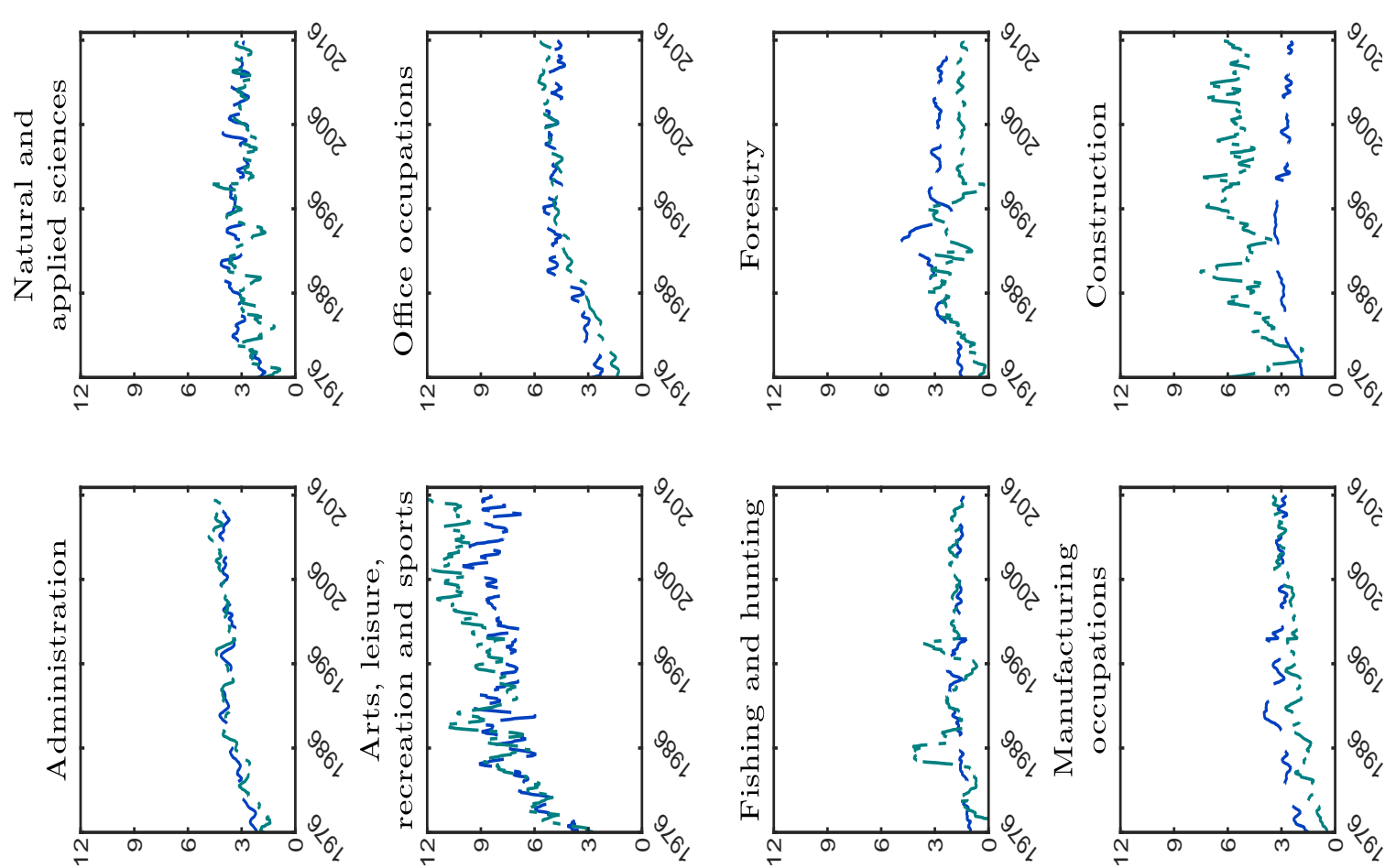

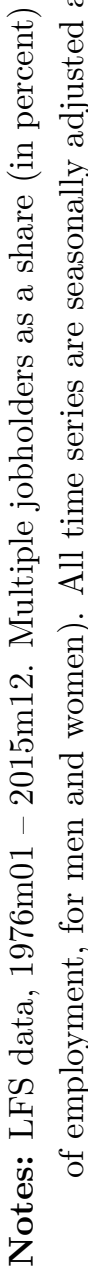

